\title{
Neuroprotection from Delayed Postischemic Administration of a Metalloporphyrin Catalytic Antioxidant
}

\author{
G. Burkhard Mackensen, ${ }^{1}$ Manisha Patel, ${ }^{2}$ Huaxin Sheng, ${ }^{1}$ Carla L. Calvi, ${ }^{1}$ Ines Batinić-Haberle, ${ }^{3}$ \\ Brian J. Day, ${ }^{2}$ Li Ping Liang, ${ }^{2}$ Irwin Fridovich, ${ }^{3}$ James D. Crapo, ${ }^{2}$ Robert D. Pearlstein, ${ }^{4}$ and \\ David S. Warner ${ }^{1,4}$ \\ ${ }^{1}$ Department of Anesthesiology, Duke University Medical Center, Durham, North Carolina 27710, ${ }^{2}$ Department of \\ Medicine, National Jewish Medical and Research Center, Denver, Colorado 80206, and Departments of ${ }^{3 B i o c h e m i s t r y}$ \\ and ${ }^{4}$ Surgery, Duke University Medical Center, Durham, North Carolina 27710
}

Reactive oxygen species contribute to ischemic brain injury. This study examined whether the porphyrin catalytic antioxidant manganese (III) meso-tetrakis ( $N$-ethylpyridinium-2yl)porphyrin (MnTE-2-PyP ${ }^{5+}$ ) reduces oxidative stress and improves outcome from experimental cerebral ischemia. Rats that were subjected to $90 \mathrm{~min}$ focal ischemia and $7 \mathrm{~d}$ recovery were given MnTE-2-PyP ${ }^{5+}$ (or vehicle) intracerebroventricularly 60 min before ischemia, or 5 or 90 min or 6 or $12 \mathrm{hr}$ after reperfusion. Biomarkers of brain oxidative stress were measured at 4 hr after postischemic treatment (5 min or $6 \mathrm{hr}$ ). MnTE-2-PyP ${ }^{5+}$, given 60 min before ischemia, improved neurologic scores and reduced total infarct size by $70 \%$. MnTE-2-PyP ${ }^{5+}$, given 5 or 90 min after reperfusion, reduced infarct size by $70-77 \%$ and had no effect on temperature. MnTE-2-PyP ${ }^{5+}$ treatment $6 \mathrm{hr}$ after ischemia reduced total infarct volume by $54 \%$ (vehicle, $131 \pm$ $60 \mathrm{~mm}^{3}$; MnTE-2-PyP ${ }^{5+}, 300 \mathrm{ng}, 60 \pm 68 \mathrm{~mm}^{3}$ ). Protection was observed in both cortex and caudoputamen, and neuro-

Increased superoxide anion $\left(\mathrm{O}_{2}^{-}\right)$formation is a component of acute brain injury. Focal cerebral ischemia (Fabian et al., 1995; Peters et al., 1998) and traumatic brain injury (Kontos and Wei, 1986) cause a sustained increase in the formation of $\mathrm{O}_{2}^{-}$. Indirect evidence for a sustained increase in reactive oxygen species production in injured brain has also been derived from use of salicylate hydroxyl radical trap microdialysis techniques after global ischemia (Globus et al., 1995a) and head injury (Globus et al., 1995b) in the rat. Evidence for significant increases in $\mathrm{O}_{2}^{-}$has been found as late as 3-4 d after global ischemia in the gerbil (Yamaguchi et al., 1998).

The significance of increased $\mathrm{O}_{2}^{-}$production in the pathogenesis and evolution of acute brain injury has not been resolved. Numerous studies have investigated the therapeutic efficacy of antioxidant compounds in both animal models and humans (Forsman et al., 1988; Matsumiya et al., 1991; Uyama et al., 1992; Muizelaar et al., 1993). Results have been mixed, and issues of

Received Feb. 1, 2001; revised April 6, 2001; accepted April 13, 2001.

This work was supported by United States Public Health Service Grants R01 NS38944-02, U10 HL 63397, and PO1 HL 31992, and Incara Pharmaceuticals Corporation (Research Triangle Park, NC). G.B.M. was supported by a postdoctoral stipend through the German Academic Exchange Service. We are grateful to Ann D. Brinkhous for expert technical assistance.

Correspondence should be addressed to Dr. David S. Warner, Department of Anesthesiology, Box 3094, Duke University Medical Center, Durham, NC 27710. E-mail: warne002@mc.duke.edu.

Copyright (C) 2001 Society for Neuroscience $0270-6474 / 01 / 214582-11 \$ 15.00 / 0$ logic scores were improved. No MnTE-2-PyP ${ }^{5+}$ effect was observed if it was given $12 \mathrm{hr}$ after ischemia. MnTE-2-PyP ${ }^{5+}$ prevented mitochondrial aconitase inactivation and reduced 8-hydroxy-2'-deoxyguanosine formation when it was given 5 min or $6 \mathrm{hr}$ after ischemia. In mice, MnTE-2-PyP ${ }^{5+}$ reduced infarct size and improved neurologic scores when it was given intravenously $5 \mathrm{~min}$ after ischemia. There was no effect of 150 or 300 ng of MnTE-2-PyP ${ }^{5+}$ pretreatment on selective neuronal necrosis resulting from $10 \mathrm{~min}$ forebrain ischemia and $5 \mathrm{~d}$ recovery in rats. Administration of a metalloporphyrin catalytic antioxidant had marked neuroprotective effects against focal ischemic insults when it was given up to $6 \mathrm{hr}$ after ischemia. This was associated with decreased postischemic superoxidemediated oxidative stress.

Key words: free radical; superoxide; brain; ischemia; metalloporphyrin; rat; mouse; mimetic bioavailability of the various compounds have not been resolved (Haun et al., 1991). Consequently, early enthusiasm for use of antioxidants to treat acute brain injury diminished.

Recently, however, interest in the role of antioxidants in ischemic brain injury has been renewed by results of studies involving murine mutants. Upregulation of synthesis of the different superoxide dismutase (SOD) isoenzymes has been shown to substantively reduce global (Murakami et al., 1997; Sheng et al., 2000) and focal (Yang et al., 1994; Sheng et al., 1999b) ischemic injury and traumatic brain injury (Mikawa et al., 1996; Pineda et al., 2001). Consistent with this, targeted deletion of the genetic codes for $\mathrm{Cu}, \mathrm{Zn}$-SOD and extracellular SOD (EC-SOD) worsens outcome from focal ischemia (Kondo et al., 1997; Sheng et al., 1999a). These data, in conjunction with data showing sustained reactive oxygen species formation after cerebral injury, allow a mechanism of action for pharmacologic agents and a therapeutic window of potential clinical relevance. In this context, we have examined the neurochemical and histologic-neurologic effects of a novel metalloporphyrin catalytic antioxidant, manganese(III) meso-tetrakis (N-ethylpyridinium-2-yl)porphyrin (MnTE-2$\mathrm{PyP}^{5+}$ ) (Batinić-Haberle et al., 1998, 1999; Batinić-Haberle, 2001), in rodent models of cerebral ischemia.

\section{MATERIALS AND METHODS}

Characterization of the antioxidant properties of MnTE-2-PyP $P^{5+}$ (AEOL10113). The redox potential of MnTE-2-PyP ${ }^{5+}$ was determined by cyclic voltametry as previously described (Batinić-Haberle et al., 1997, 
1998). Superoxide dismutase activity was determined indirectly using cytochrome c reduction as previously described (McCord and Fridovich, 1969). Catalase activity was determined using a Clark electrode to measure oxygen formation from the dismutation of $1 \mathrm{~mm}$ hydrogen peroxide (Day et al., 1997). Inhibition of lipid peroxidation by iron and ascorbate in rat brain homogenates was performed as previously described (Day et al., 1999).

The following studies were approved by the Duke University Animal Care and Use Committee.

Rat focal ischemia (experiments 1-7). Male Wistar rats (age 8-10 weeks; Harlan Sprague Dawley, Indianapolis, IN) were anesthetized with sodium pentobarbital $(64 \mathrm{mg} / \mathrm{kg}$, i.p.) and positioned in a stereotactic head frame. Using aseptic technique, the skin was infiltrated with $1.0 \%$ lidocaine, and a midline scalp incision was made. A burr hole was drilled over the left hemisphere, $7.2 \mathrm{~mm}$ anterior to the interaural line and $1.4 \mathrm{~mm}$ lateral to the sagittal suture. An intracerebroventricular cannula (33 ga) was positioned with the tip in the left lateral ventricle. The cannula was fixed in place with two cranial screws and stabilized with orthodontic cement. The wound was closed with suture, and animals were allowed to awaken. Rats were then returned to their cages with ad libitum access to water (with addition of $1 \mathrm{mg} / 1 \mathrm{ml}$ tetracycline) and food for recovery.

After 2-3 d of recovery, rats were fasted but allowed ad libitum access to water for $12-16 \mathrm{hr}$ before transient middle cerebral artery occlusion (MCAO). Rats were then anesthetized with halothane in $\mathrm{O}_{2}$. After tracheal intubation, the lungs were mechanically ventilated to maintain normocapnia. A 22 ga needle thermistor was percutaneously placed adjacent to the skull beneath the temporalis, and pericranial temperature was servoregulated at $37.5 \pm 0.1^{\circ} \mathrm{C}$ by surface heating or cooling throughout the anesthetic. The inspired halothane concentration was adjusted to $1.0-1.5 \%$ in $30 \% \mathrm{O}_{2}$ /balance $\mathrm{N}_{2}$. The tail artery was cannulated to monitor mean arterial pressure (MAP) and sample blood. Then the animals were prepared for filament MCAO (Zea Longa et al., 1989). A midline cervical incision was made, and the right common carotid artery was identified. The external carotid artery (ECA) was isolated, and the occipital, superior thyroid, and external maxillary arteries were ligated and divided. The internal carotid artery was dissected distally until the origin of the pterygopalatine artery was visualized. After surgical preparation, a $20 \mathrm{~min}$ interval was allowed for physiological stabilization.

Five minutes before onset of MCAO, rats received heparin (50 IU, i.v.). A nylon monofilament (diameter, $0.25 \mathrm{~mm}$ ) prepared with a silicone tip (Belayev et al., 1996) was inserted into the stump of the external carotid artery and passed distally through the internal carotid artery (23 $\mathrm{mm}$ from carotid bifurcation) until a slight resistance was felt. The filament was secured, and the wound was closed. At MCAO onset, halothane was reduced to $0.8 \%$.

Before removal of the filament, the inspired halothane concentration was increased to $1 \%$. After 90 min of MCAO, the occlusive filament was removed, and the neck wound was closed with suture. The anesthetic state and pericranial temperature regulation were continued for an additional $90 \mathrm{~min}$. The tail artery catheter was removed, and the wound was closed with suture. Then, halothane was discontinued. On recovery of the righting reflex, animals were extubated and placed in an $\mathrm{O}_{2}$ enriched environment $\left(40 \% \mathrm{O}_{2}\right.$ in room air) for overnight recovery. Animals were returned then to their home cages.

For experiment 1 ( $1 \mathrm{hr}$ before treatment), rats $(n=13-14$ per group) were randomly assigned to receive MnTE-2-PyP ${ }^{5+}(150$ or $300 \mathrm{ng}$ in 10 $\mu \mathrm{l}$ of vehicle) or $10 \mu \mathrm{l}$ of vehicle (Dulbecco's PBS) via the intracerebroventricular cannula. MnTE-2-PyP ${ }^{5+}$ or vehicle was injected over a $5 \mathrm{~min}$ interval beginning $60 \mathrm{~min}$ before onset of ischemia.

For experiment 2 (5 or $90 \mathrm{~min}$ after treatment), all rats received an intracerebroventricular injection at two different times. Rats $(n=16$ per group) were randomly assigned to receive the following: (1) $300 \mathrm{ng}$ of MnTE-2-PyP ${ }^{5+} 5$ min after reperfusion from MCAO and vehicle $90 \mathrm{~min}$ later, (2) vehicle at $5 \mathrm{~min}$ after MCAO and $300 \mathrm{ng}$ of MnTE-2-PyP ${ }^{5+} 90$ min later, or (3) vehicle only at both injection intervals. All injectate volumes were $10 \mu \mathrm{l}$. Animals were awakened from anesthesia $15 \mathrm{~min}$ after completion of the second injection.

For experiment 3 (6 hr after treatment), rats $(n=16$ per group) underwent $90 \mathrm{~min}$ of MCAO as described above. Ninety minutes after onset of reperfusion, the rats were awakened from anesthesia. At $6 \mathrm{hr}$ after onset of reperfusion, these animals were briefly anesthetized with halothane via snout cone and randomly assigned to receive the following via the intracerebroventricular cannula: (1) $300 \mathrm{ng}$ of $\mathrm{MnTE}^{2}-\mathrm{PyP}^{5+}$, or (2) vehicle $(10 \mu l)$. Rats were awakened then and allowed to recover.
In experiment 4 (12 $\mathrm{hr}$ after treatment), the experimental protocol was identical to experiment 3, with the exception that $300 \mathrm{ng}$ of MnTE-2$\mathrm{PyP}^{5+}$ or vehicle $(10 \mu \mathrm{l})$ was injected intracerebroventricularly at $12 \mathrm{hr}$ after onset of reperfusion ( $n=15$ per group).

Seven days after ischemia, rats in experiments 1-4 underwent a standardized neurologic examination designed to evaluate sensorimotor function (Garcia et al., 1995). With the observer blinded to group assignment, this test explored six different functions (spontaneous activity, movement symmetry, forepaw outstretching, climbing, body proprioception, and response to vibrissae touch). The individual performance in each test was rated with a $0-3$ point score. The score that was given to each animal at the completion of the testing was the sum of all six individual scores, 0 being the minimum (worst) and 18 being the maximum (best) score.

After neurologic evaluation, animals were weighed, anesthetized with $3-5 \%$ halothane, and decapitated. The brains were removed, frozen at $-40^{\circ} \mathrm{C}$ in 2-methylbutane, and stored at $-70^{\circ} \mathrm{C}$. Serial quadruplicate $20-\mu \mathrm{m}$-thick coronal sections were taken using a cryotome at $660 \mu \mathrm{m}$ intervals over the rostrocaudal extent of the infarct. The sections were dried and stained with hematoxylin and eosin.

Infarct volumes were measured by digitally sampling stained sections with a video camera controlled by an image analyzer. The image of each section was stored as a $1280 \times 960$ calibrated pixel matrix. The digitized image was then displayed on a video monitor. With the observer blinded to experimental conditions, infarct borders in both cortex and subcortex were individually outlined (corpus callosum excluded) using an operatorcontrolled cursor. The area of infarct (in square millimeters) was determined by counting pixels contained within the outlined regions of interest. Infarct volumes (in cubic millimeters) were computed as running sums of infarct area multiplied by the known interval (e.g., $660 \mu \mathrm{m}$ ) between sections over the extent of the infarct calculated as an orthogonal projection.

For experiment 5, rats underwent intracerebroventricular cannula placement and MCAO (90 min) as described above. At the time of MCAO preparation, a radiotelemetered thermistor (type VM-FH; Mini Mitter Co., Sunriver, OR), accuracy $\pm 0.1^{\circ} \mathrm{C}$, was implanted into the peritoneal cavity to track core temperature. The thermistor had been previously calibrated (within the range of 35.0 to $40.0^{\circ} \mathrm{C}$ ) in a circulating water bath against a mercury thermometer. This allowed extrapolation of temperatures from calibration points in accordance with the radiofrequency emitted by the probe. Radiofrequency signals from the probe were received (Telemetry Receiver model RA1010; Data Science, St. Paul, MN), digitized, and processed through a computer (4DX-33V, Gateway 2000; Gateway, North Sioux City, SD) with custom-made software to determine temperature. Five minutes after ischemia, either $10 \mu \mathrm{l}$ of intraventricular vehicle $(n=3)$ or $300 \mathrm{ng}$ of MnTE-2$\mathrm{PyP}^{5+}(n=3)$ was injected. Ninety minutes after onset of reperfusion, the animals were allowed to awaken. Core temperature was monitored for the subsequent $20 \mathrm{hr}$.

For experiment 6 [aconitase, fumarase, and 8-hydroxy-2'deoxyguanosine (8-OHdG) assays ], rats underwent 90 min MCAO. Five minutes after onset of reperfusion, rats were treated intracerebroventricularly with $300 \mathrm{ng}$ of MnTE-2-PyP ${ }^{5+}(n=6)$ or vehicle $(n=6 ; 10 \mu \mathrm{l})$. Animals were allowed to awaken $90 \mathrm{~min}$ later. At $4 \mathrm{hr}$ after onset of reperfusion, these rats were anesthetized with halothane and decapitated; the brains were removed and dissected. The hindbrain was discarded. The forebrain was divided into hemispheres, and the cortex was separated. Cortical tissue samples were weighed and then frozen at $-90^{\circ} \mathrm{C}$ until analytic techniques were performed within the subsequent 2 weeks.

For experiment 7 , all conditions were identical to experiment 6 , with the exception of changes in timing of postischemic administration of MnTE-2-PyP ${ }^{5+}$ and brain harvesting. In this study, rats were awakened after recirculation from MCAO. Six hours later, rats were anesthetized briefly with halothane by snout mask. MnTE-2-PyP ${ }^{5+}(300 \mathrm{ng}, n=8)$ or vehicle $(10 \mu \mathrm{l}, n=8)$ was injected intracerebroventricularly, replicating the conditions in experiment 3 . Rats were awakened then. At $10 \mathrm{hr}$ after reperfusion, rats were killed with a halothane overdose. The brains were dissected as described for experiment 6 and analyzed for aconitase and fumarase activities and 8-OHdG.

For aconitase and fumarase activity assays, cortical tissue $(\sim 75 \mathrm{mg}$ samples) was homogenized with a Dounce tissue grinder (Wheaton, Millville, NJ) in mitochondrial isolation buffer (70 mM sucrose, $210 \mathrm{~mm}$ mannitol, $5 \mathrm{~mm}$ Tris-HCl, $1 \mathrm{~mm}$ EDTA, $20 \mu \mathrm{M}$ flourocitrate, $\mathrm{pH}$ 7.4). After homogenization, the suspensions were centrifuged at $600 \times g$ for 
$5 \mathrm{~min}$ at $4^{\circ} \mathrm{C}$; the supernatant was transferred to a chilled Eppendorf tube and centrifuged at $17,000 \times g$ for $10 \mathrm{~min}$ at $4^{\circ} \mathrm{C}$. Mitochondrial pellets were frozen in liquid nitrogen and stored at $-80^{\circ} \mathrm{C}$ for use within 2 weeks. Immediately before aconitase and fumarase activity measurements, mitochondrial fractions were resuspended and sonicated for $2 \mathrm{sec}$. Aconitase and fumarase activities were measured as previously described (Patel et al., 1996). Aconitase activity was measured spectrophotometrically by monitoring the formation of cis-aconitate from isocitrate at 240 $\mathrm{nm}$ in $50 \mathrm{~mm}$ Tris- $\mathrm{HCl}, \mathrm{pH} 7.4$, containing (in $\mathrm{mm}$ ): $0.6 \mathrm{MnCl}_{2}$ and 20 isocitrate at $25^{\circ} \mathrm{C}$ (Krebs and Holzach, 1952). Fumarase activity was measured by monitoring the increase in absorbance at $240 \mathrm{~nm}$ at $25^{\circ} \mathrm{C}$ in a $1 \mathrm{ml}$ reaction mixture containing (in $\mathrm{mm}$ ): $0.1 \mathrm{~L}$-malate, 30 potassium phosphate, $\mathrm{pH} 7.4$ (Racker, 1950). Protein concentrations were measured using Coomassie Plus reagents.

For measurement of $8-\mathrm{OHdG}$ and 2 -deoxyguanosine $(\mathrm{dG})$, cortical tissue was homogenized for DNA extraction with a Dounce tissue grinder in a $1 \%$ SDS, $10 \mathrm{~mm}$ Tris, $1 \mathrm{~mm}$ EDTA, pH 7.4 buffer and incubated in a $0.5 \mathrm{mg} / \mathrm{ml}$ proteinase buffer at $55^{\circ} \mathrm{C}$ overnight. Homogenates were incubated with RNase $(0.1 \mathrm{mg} / \mathrm{ml})$ at $50^{\circ} \mathrm{C}$ for $10 \mathrm{~min}$ and extracted twice with chloroform-isoamyl alcohol $(24: 1, \mathrm{v} / \mathrm{v})$. The extracts were mixed with $1: 15 \mathrm{vol}$ of $3 \mathrm{~m}$ sodium acetate, $\mathrm{pH} 7.0$, and $2 \mathrm{vol}$ of $100 \%$ cold ethanol to precipitate DNA at $-20^{\circ} \mathrm{C}$ for $1 \mathrm{hr}$. The samples were centrifuged at $17,000 \times g$ for $10 \mathrm{~min}$. The resultant DNA pellets were washed twice with $70 \%$ ethanol, air-dried for $3 \mathrm{~min}$, and dissolved in $100 \mu \mathrm{l}$ of $10 \mathrm{~mm}$ Tris, $1 \mathrm{~mm}$ EDTA, pH 7.4.

Cellular DNA digestion was performed as previously described (Kasai et al., 1986). The oxidative DNA product $8-\mathrm{OHdG}$ was measured with HPLC using an electrochemical detector (CoulArray model 5600; ESA, Inc., Chelmsford, MA) (Arashidani et al., 1998; Liang et al., 2000). Analytes were detected on two coulometric array cell modules, each containing four electrochemical sensors attached in series. UV detection for $\mathrm{dG}$ was set at $260 \mathrm{~nm}$ at 0.005 AUFS (absorbance units full scale) (model 520). Analytes were separated on a $3 \mu \mathrm{m}, 150 \times 4.6 \mathrm{~mm}$ column (YMC, Wilmington, NC). The mobile phase was composed of $50 \mathrm{~mm}$ sodium acetate, $5 \%$ methanol, $\mathrm{pH}$ 5.2. Electrochemical detector potentials for $8-\mathrm{OHdG}$ and $\mathrm{dG}$ were 120/230/280/420/600/750/840/900 mV (vs palladium). The flow rate was $1.0 \mathrm{ml} / \mathrm{min}$. The temperature of the column and detectors was maintained at $31^{\circ} \mathrm{C}$.

Mouse focal ischemia (experiments 8-9). Male C57/B16J mice (The Jackson Laboratory, Bar Harbor, ME) at 8-10 weeks of age were used for these studies.

For experiment 8 (intravenous MnTE-2-PyP ${ }^{5+}$ ), mice were fasted overnight from food but allowed ad libitum access to water. Mice were anesthetized then with $1.0-1.5 \%$ halothane in $50 \% \mathrm{O}_{2} /$ balance $\mathrm{N}_{2}$. The trachea was intubated, and the lungs were mechanically ventilated. A femoral artery was cannulated for measurement of blood pressure and arterial blood gases. Via a midline cervical skin incision, the right common carotid artery was identified. The ECA was ligated and transected. The internal carotid artery was dissected distally until the origin of the pterygopalatine artery was visualized. Finally, the right jugular vein was cannulated.

After surgical preparation, a 15 min interval was allowed for physiological stabilization. Pericranial temperature was continuously monitored and servoregulated with surface heating-cooling at $37.0^{\circ} \mathrm{C}$ throughout the procedure. Inspired halothane concentration was adjusted to prohibit motor response to surgical stimuli but allow support of arterial blood pressure.

A 6-0 nylon monofilament, blunted at the tip in a flame and then lightly coated with silicone, was inserted into the proximal external carotid artery stump and advanced $\approx 11 \mu \mathrm{m}$ so as to occlude the MCA. Pilot studies were performed to define the maximal duration of MCAO that would allow a high survival rate in the vehicle-treated group under these experimental conditions. An MCAO interval of $90 \mathrm{~min}$ was found to cause $<10 \%$ mortality yet still produce a large cerebral infarct. Accordingly, all experimental groups were subjected to $90 \mathrm{~min}$ of MCAO, after which the occlusive filament was removed.

Pilot studies were also performed to determine the maximal allowable intravenous dose of MnTE-2-PyP ${ }^{5+}$ that would not elicit behavioral side effects. The effects of intravenous doses as high as $5 \mathrm{mg} / \mathrm{kg}$ were examined in mice not subjected to ischemia. No adverse effects were observed. When the same dose was given to mice at 5 min after 90 min MCAO, behavioral changes including proptosis, ataxia, and hypersensitivity to sound were noted $\sim 2 \mathrm{hr}$ after injection. The dose was progressively decreased until these effects were absent in postischemic animals. That dose was found to be $2 \mathrm{mg} / \mathrm{kg}$. Accordingly, the following dosing groups were generated: (1) high dose $(n=18)$, MnTE-2-PyP ${ }^{5+}(2 \mathrm{mg} / \mathrm{kg}$, i.v. $)$ in $15 \mu \mathrm{l}$ of PBS; (2) low dose $(n=17), \mathrm{MnTE}^{2}-\mathrm{PyP}^{5+}(1 \mathrm{mg} / \mathrm{kg}$, i.v. $)$ in 15 $\mu \mathrm{l}$ of PBS; and (3) vehicle ( $n=15), 15 \mu \mathrm{l}$ of PBS intravenous.

Intravenous injections were made over a 5 min interval beginning 5 min after onset of reperfusion. The arterial and jugular catheters were removed, and the wounds were infiltrated with lidocaine and closed with suture. Halothane was discontinued, and the mice were allowed to awaken. When spontaneous ventilation and the righting reflex recovered, the trachea was extubated. Mice were placed in an $\mathrm{O}_{2}$-enriched environment (fractional inspired $\mathrm{O}_{2}=50 \%$ ) for $\sim 1 \mathrm{hr}$. During that interval, rectal temperature was monitored and controlled at $37.0^{\circ} \mathrm{C}$. Then the mice were returned to their cages.

After $24 \mathrm{hr}$ of reperfusion, all animals underwent neurologic evaluation. Each mouse was assigned a score of $0-4$, where 0 represented no observable neurological deficit; 1 , failure to extend the left forepaw; 2 , circling to the left; 3 , falling to the left; and 4, cannot walk spontaneously (Yang et al., 1994). Neurological examination was performed by one observer blinded to group assignment.

After neurological evaluation, animals were anesthetized with halothane and decapitated. The brains were removed and frozen at $-20^{\circ} \mathrm{C}$. Using a cryotome, six $20-\mu \mathrm{m}$-thick coronal sections were taken at $320 \mu \mathrm{m}$ intervals over the rostrocaudal extent of the infarct. The sections were dried and stained with hematoxylin and eosin.

Infarct volume was measured as described for the rat focal ischemia studies. Infarct volumes (in cubic millimeters) were computed as running sums of infarct area multiplied by the known interval (e.g., $320 \mu \mathrm{m}$ ) between sections over the extent of the infarct, expressed as an orthogonal projection.

For experiment 9 (intracerebroventricular MnTE-2-PyP ${ }^{5+}$ ), procedures in mice were identical to those described above with the following exceptions. A right lateral ventricular cannula was placed with the following technique. Anesthesia was provided by a subcutaneous injection of $75 \mathrm{mg} / \mathrm{kg}$ ketamine, $4 \mathrm{mg} / \mathrm{kg}$ xylazine, and $0.8 \mathrm{mg} / \mathrm{kg}$ acepromazine. After infiltration with $0.02 \mathrm{ml}$ of $1 \%$ lidocaine behind the ears and in the scalp, the animal was placed in a stereotactic frame. The scalp was incised. A burr hole was made over the left hemisphere, and the dura was incised. A cannula (model 3300 PM; Plastics One, Roanoke, VA) was placed in the left lateral ventricle using the following coordinates: bregma $-0.5 \mathrm{~mm}$, lateral $+1.0 \mathrm{~mm}$, at a depth of $-1.4 \mathrm{~mm}$. The cannula was affixed to the skull surface with an instant adhesive. The wound was closed with suture, and the animal was removed from the head frame and allowed to awaken. During surgical preparation for temporary MCAO, the right jugular vein was not cannulated.

Two to three days after implantation of the cannula, mice were surgically prepared and subjected to $50 \mathrm{~min}$ filament $\mathrm{MCAO}$ as described for experiment 8 . Five minutes after removal of the occlusive filament, mice were randomly assigned to one of three groups: (1) high dose $(n=16), 100 \mathrm{ng}$ of MnTE-2-PyP ${ }^{5+}$ (intracerebroventricular) in $1 \mu$ l of PBS; (2) low dose $(n=$ 15), $50 \mathrm{ng}$ of MnTE-2-PyP ${ }^{5+}$ (intracerebroventricular) in $1 \mu \mathrm{l}$ of PBS; or (3) vehicle $(n=15), 1 \mu$ l of PBS (intracerebroventricular).

Pilot studies were performed to define the maximal duration of MCAO that would allow $>90 \%$ survival in mice treated with intracerebroventricular vehicle. That interval was found to be $50 \mathrm{~min}$ and therefore was used in this experiment. All intracerebroventricular injections were performed over an interval of $5 \mathrm{~min}$ using a $1 \mu \mathrm{l}$ Hamilton syringe. As in the rat, high doses of intracerebroventricular MnTE-2-PyP ${ }^{5+}$ were found to cause a rapid onset of behavioral responses, including proptosis, ataxia, and hypersensitivity to sound. Pilot studies determined the threshold dose required to elicit these signs to be $200 \mathrm{ng}$. Therefore, we elected to study one-half that dose as our high dose regimen in the outcome study.

Mice were recovered from anesthesia and allowed to survive $24 \mathrm{hr}$. Neurologic examination and histologic processing for measurement of infarct volume was as described for experiment 8.

Rat near-complete forebrain ischemia (experiment 10). Male Sprague Dawley rats (age, 8-10 weeks; Harlan Sprague Dawley), underwent placement of a left intracerebroventricular cannula as described above. The coordinates for positioning the cannula were $1.4 \mathrm{~mm}$ lateral to midline and $1.5 \mathrm{~mm}$ posterior to bregma.

Two to three days later, the rats were anesthetized with halothane. After orotracheal intubation, the lungs were mechanically ventilated $\left(30 \% \mathrm{O}_{2} /\right.$ balance $\mathrm{N}_{2}$ ). The inspired halothane concentration was reduced to $1.0-1.5 \%$. Surgery was performed with aseptic technique, and all surgical fields were infiltrated with $1 \%$ lidocaine. The tail artery was cannulated and used to monitor MAP and to sample blood. Via a ventral 
neck incision, the right jugular vein was cannulated for blood withdrawal. The common carotid arteries were encircled with suture. The vagus nerves and cervical sympathetic plexus were left intact. Bilateral cortical EEG was monitored from active subdermal electrodes positioned over the parietal cortex bilaterally and a ground lead in the tail.

A 22 ga needle thermistor was percutaneously placed adjacent to the skull beneath the temporalis, and pericranial temperature was servoregulated at $37.5 \pm 0.1^{\circ} \mathrm{C}$ by surface heating or cooling. Heparin (50 IU, i.v.) was given. Inspired halothane was reduced to $0.8 \%$. A 20 min interval was allowed for physiological stabilization. Ventilation was adjusted to maintain normocapnia.

Rats were randomly assigned to one of three groups and received either 150 or $300 \mathrm{ng}$ of intracerebroventricular MnTE-2-PyP ${ }^{5+}$ or vehicle (10 $\mu \mathrm{l}) 1 \mathrm{hr}$ before onset of ischemia over $5 \mathrm{~min}$.

Forebrain ischemia was caused by rapid venous blood withdrawal to reduce $\mathrm{MAP}$ to $30 \mathrm{mmHg}$ combined with bilateral carotid occlusion using temporary aneurysm clips (Smith et al., 1984; Gionet et al., 1992). Ischemia persisted for $10 \mathrm{~min}$ and was confirmed electroencephalographically. To terminate ischemia, shed blood was reinfused, and the aneurysm clips were removed. $\mathrm{NaHCO}_{3}(0.3 \mathrm{~mm}$, i.v. $)$ was given to counteract systemic acidosis.

The anesthetic state and pericranial temperature regulation were continued for an additional $60 \mathrm{~min}$. Then catheters were removed, and the wounds were closed with suture. Halothane was discontinued. On recovery of the righting reflex, animals were extubated and placed in an oxygen-enriched environment $\left(40 \% \mathrm{O}_{2}\right.$ in room air) for overnight recovery. Animals were returned then to their home cages.

On the fifth postoperative day, with the observer blinded to group assignment, motor function tests were performed according to an established protocol, including assays of prehensile traction and balance beam performance (Combs and D'Alecy, 1987; Gionet et al., 1991). The motor score was graded on a $0-9$ scale (best score $=9$ ). Rats were anesthetized with 3-5\% halothane and underwent in situ brain fixation by intracardiac injection of buffered $10 \%$ formalin. After $24 \mathrm{hr}$, the brains were removed and stored in $10 \%$ formalin. Paraffin-embedded brain sections were serially cut (5 $\mu \mathrm{m}$ thick) and stained with acid fuchsin-celestine blue. With the investigator blinded to group assignment, injury to the CA1 sector of the hippocampus (bregma -4.0) was evaluated by light microscopy. Viable and nonviable neurons were manually counted, and the percentage of nonviable neurons was calculated (\% dead CA1). At the level in which the septal nuclei were widest, damage in the neocortex and caudoputamen was graded on a $0-3$ scale $(0$, no damaged neurons; 1 , $1-30 \%$ neurons damaged; $2,30-60 \%$ neurons damaged; $3,>60 \%$ of neurons damaged) (Coimbra et al., 1996). Values from the hemisphere with the worst damage in each animal were used for the final analysis.

Statistical analysis. For focal ischemia (experiments 1-4, 8 and 9), subcortical, cortical, and total infarct volumes and physiologic values were compared by one-way ANOVA. For experiments with three groups, post hoc testing was performed with Fisher's protected least squares differences test when indicated by a significant $F$ ratio. Neurologic scores were compared among groups by the Kruskal-Wallis $H$ statistic or Mann-Whitney $U$ statistic. Peritoneal temperature values were compared qualitatively (experiment 5). Aconitase and fumarase values and $8-\mathrm{OHdG} / \mathrm{dG}$ ratios (experiments 6 and 7) were analyzed with one-way or two-way ANOVA where appropriate. For forebrain ischemia outcome (experiment 10), physiologic values and hippocampal CA1 damage were compared by one-way ANOVA. Cortical and striatal selective neuronal necrosis and total motor scores were compared among groups using the Kruskal-Wallis $H$ statistic or Mann-Whitney $U$ statistic where appropriate. Parametric data are reported as mean \pm SD. Nonparametric data are reported as median \pm interquartile range. Statistical significance was assumed when $p<0.05$.

\section{RESULTS}

\section{Biochemical characteristics of the catalytic antioxidant, MnTE-2-PyP ${ }^{5+}$}

Recent advances in our understanding of the chemical requirements for producing more potent catalytic antioxidants have led to the development of MnTE-2-PyP ${ }^{5+}$ (Fig. 1) (Batinić-Haberle et al., 1998). Manganopyridyl porphyrins have been shown to have SOD-like activity (Pasternack et al., 1981). However, the compound evaluated, MnTM-4-PyP ${ }^{5+}$, had a rate constant that was only $0.18 \%$ of that of $\mathrm{Cu}, \mathrm{Zn}$-SOD. In addition, MnTM-4-

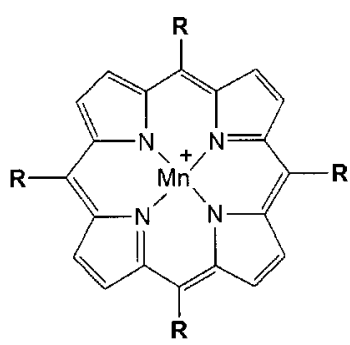

$\mathbf{R}$

\section{Catatalytic Antioxidant Manganese Porphyrins}

Figure 1. Structures of catalytic antioxidant porphyrins that contain cationic, pyridyl side groups: manganese(111)-tetrakis- $(N$-methylpyridinium-4-yl)porphyrin (MnTM-4-PyP ${ }^{5+}$ ) or manganese(111)-tetrakis( $N$-ethylpyridinium-2-yl)porphyrin (MnTE-2-PyP ${ }^{5+}$ ).

$\mathrm{PyP}^{5+}$ had little activity in mammalian cells, possibly because of the binding of this molecule to DNA (Batinić-Haberle et al., 1998). Altering the position of the nitrogen in the pyridyl group from the para to the ortho position (MnTE-2-PyP ${ }^{5+}$ ) significantly changed the redox potential toward that of the native SOD enzymes (Table 1). This small change in structure resulted in a 20 -fold increase in SOD activity, a 3 -fold increase in catalase activity, and a 15 -fold increase in its ability to protect lipids from oxidative stress. It also greatly reduced binding of this molecule to DNA and increased its activity in mammalian biological systems.

\section{Experiment 1: MnTE-2-PyP ${ }^{5+}$ pretreatment attenuates focal ischemia infarct size and improves neurologic outcome}

Physiologic values are summarized in Table 2. There were no significant differences among groups, with the exception of day 7 postischemia body weight, which was greater in the MnTE-2$\mathrm{PyP}^{5+}$-treated animals $(p=0.004)$. Neurologic scores were improved in MnTE-2-PyP ${ }^{5+}$-treated animals (vehicle, $10 \pm 2 ; 150$ ng, $12 \pm 4 ; 300 \mathrm{ng}, 13 \pm 4 ; p=0.001$ ). When administered before ischemia, MnTE-2-PyP ${ }^{5+}$ reduced subcortical (vehicle, $86 \pm 33$ $\left.\mathrm{mm}^{3} ; 150 \mathrm{ng}, 39 \pm 21 \mathrm{~mm}^{3} ; 300 \mathrm{ng}, 34 \pm 27 \mathrm{~mm}^{3} ; p<0.0001\right)$, cortical (vehicle, $102 \pm 54 \mathrm{~mm}^{3} ; 150 \mathrm{ng}, 22 \pm 30 \mathrm{~mm}^{3} ; 300 \mathrm{ng}$, $13 \pm 27 \mathrm{~mm}^{3} ; p<0.0001$ ), and total (vehicle, $188 \pm 82 \mathrm{~mm}^{3} ; 150$ $\left.\mathrm{ng}, 61 \pm 48 \mathrm{~mm}^{3} ; 300 \mathrm{ng}, 47 \pm 51 \mathrm{~mm}^{3} ; p<0.0001\right)$ infarct volumes.

\section{Experiments 2-5: MnTE-2-PyP ${ }^{5+}$ rescues tissue damage and neurologic function up to $6 \mathrm{hr}$ after ischemia without affecting temperature}

In experiments $2-5$, blood chemistry, MAP, and temperature values were similar to those reported for experiment 1 without differences among groups (data not shown).

In experiment 2, $300 \mathrm{ng}$ of MnTE-2-PyP ${ }^{5+}$ given at either 5 or $90 \mathrm{~min}$ after onset of reperfusion from $90 \mathrm{~min}$ of MCAO improved neurologic scores (vehicle, $9 \pm 1 ; 5 \mathrm{~min}, 13 \pm 4 ; 90 \mathrm{~min}$, $12 \pm 3 ; p=0.002$ ) and reduced subcortical (vehicle, $68 \pm 31 \mathrm{~mm}^{3}$; $\left.5 \mathrm{~min}, 32 \pm 24 \mathrm{~mm}^{3} ; 90 \mathrm{~min}, 28 \pm 14 \mathrm{~mm}^{3} ; p<0.0001\right)$, cortical (vehicle, $75 \pm 47 \mathrm{~mm}^{3} ; 5 \mathrm{~min}, 9 \pm 37 \mathrm{~mm}^{3} ; 90 \mathrm{~min}, 4 \pm 11 \mathrm{~mm}^{3}$; $p<0.0001$ ), and total (vehicle, $143 \pm 75 \mathrm{~mm}^{3} ; 5 \mathrm{~min}, 41 \pm 58$ $\left.\mathrm{mm}^{3} ; 90 \mathrm{~min}, 31 \pm 22 \mathrm{~mm}^{3} ; p<0.0001\right)$ infarct volumes.

In experiment 3, MnTE-2-PyP ${ }^{5+}$ given at $6 \mathrm{hr}$ after onset of reperfusion from $90 \mathrm{~min}$ of MCAO improved neurologic scores (vehicle, $9 \pm 1.5$; MnTE-2-PyP ${ }^{5+}, 10.5 \pm 3.0 ; p=0.05$ ) and reduced subcortical (vehicle, $67 \pm 37 \mathrm{~mm}^{3}$; MnTE-2-PyP ${ }^{5+}, 39 \pm$ 


\begin{tabular}{|c|c|c|c|c|}
\hline Antioxidants & $\begin{array}{l}\text { Redox potential } \\
\left(\mathrm{Mn}^{\mathrm{III}} / \mathrm{Mn}^{\mathrm{II}}\right)\left(E_{1 / 2}, V\right)^{a}\end{array}$ & $\begin{array}{l}\text { SOD } \\
(\mathrm{U} \text { SOD } / \mathrm{mmol})^{b}\end{array}$ & $\begin{array}{l}\text { Catalase } \\
\left(\sec ^{-1}\right)^{c}\end{array}$ & $\begin{array}{l}\text { Lipid peroxidation } \\
\text { inhibition }\left(\mathrm{IC}_{50}, \mu \mathrm{M}\right)^{d}\end{array}$ \\
\hline $\mathrm{Cu}, \mathrm{Zn}-\mathrm{SOD}$ & $+0.35^{e}$ & $1.6 \times 10^{8 f}$ & - & $15^{g}$ \\
\hline MnTM-4-PyP $\mathrm{P}^{5+}$ & $+0.06^{f}$ & $5.4 \times 10^{5 f}$ & 34 & $16^{g}$ \\
\hline MnTE-2-PyP ${ }^{5+}$ & $+0.23^{f}$ & $1.0 \times 10^{7 f}$ & 128 & 1 \\
\hline \multicolumn{5}{|c|}{$\begin{array}{l}{ }^{a} \text { Metal-centered redox potentials versus normal hydrogen electrode obtained at } \mathrm{pH} 7.8 \text { in } 0.05 \mathrm{M} \text { phosphate buffer, } 0.1 \mathrm{M} \\
\mathrm{NaCI}, 0.5 \mathrm{~mm} \text { porphyrin, and related to } \mathrm{Mn}^{\mathrm{III}} / \mathrm{Mn}^{\mathrm{II}} \text {, redox couple. }\end{array}$} \\
\hline \multicolumn{5}{|c|}{$\begin{array}{l}{ }^{b} \text { Unit of SOD activity (U SOD) is defined as the amount of antioxidant that inhibits one-half the reduction of cytochrome } \\
\text { c by superoxide. }\end{array}$} \\
\hline \multicolumn{5}{|c|}{$\begin{array}{l}{ }^{c} \text { Activity is presented as a first-order rate constant of hydrogen peroxide decay in the presence of varying concentrations of } \\
\text { metalloporphyrins in } 1 \mathrm{~mm} \text { hydrogen peroxide at } \mathrm{pH} 7.8 \text {. }\end{array}$} \\
\hline \multicolumn{5}{|c|}{$\begin{array}{l}{ }^{d} \text { The concentration of antioxidant that inhibited } 50 \% \text { of iron-ascorbate initiated lipid peroxidation of a rat brain } \\
\text { homogenate using thiobarbaturic acid reactive species as an index of lipid peroxidation. }\end{array}$} \\
\hline \multicolumn{5}{|c|}{$\begin{array}{l}e, f, g \text { Data from these antioxidants have been published previously (Lawrence and Sawyer, 1979; Batinić-Haberle et al., 1999; } \\
\text { Day et al., 1999, respectively). }\end{array}$} \\
\hline
\end{tabular}

Table 2. Physiologic values for experiment 1 (rat focal ischemia-intracerebroventricular MnTE-2-PyP ${ }^{5+}$ before treatment)

\begin{tabular}{|c|c|c|c|}
\hline & $\begin{array}{l}\text { Vehicle } \\
(n=14)\end{array}$ & $\begin{array}{l}\text { MnTE-2-PyP }{ }^{5+} \\
150 \mathrm{ng}(n=14)\end{array}$ & $\begin{array}{l}\text { MnTE-2-PyP }{ }^{5+} \\
300 \mathrm{ng}(n=13)\end{array}$ \\
\hline Preischemia body weight (gm) & $290 \pm 13$ & $286 \pm 10$ & $289 \pm 15$ \\
\hline Day 7 body weight (gm) & $257 \pm 54$ & $302 \pm 22^{*}$ & $306 \pm 36^{*}$ \\
\hline \multicolumn{4}{|l|}{$10 \mathrm{~min}$ before ischemia } \\
\hline MAP (mmHg) & $83 \pm 19$ & $91 \pm 15$ & $84 \pm 15$ \\
\hline Arterial $\mathrm{pH}$ & $7.40 \pm 0.04$ & $7.41 \pm 0.03$ & $7.40 \pm 0.03$ \\
\hline $\mathrm{PaCO}_{2}(\mathrm{mmHg})$ & $39 \pm 3$ & $38 \pm 2$ & $38 \pm 4$ \\
\hline $\mathrm{PaO}_{2}(\mathrm{mmHg})$ & $154 \pm 23$ & $184 \pm 38$ & $178 \pm 34$ \\
\hline Glucose (mg/dl) & $112 \pm 11$ & $109 \pm 15$ & $96 \pm 16$ \\
\hline Hematocrit $(\%)$ & $39 \pm 1$ & $40 \pm 1$ & $40 \pm 2$ \\
\hline Pericranial temperature $\left({ }^{\circ} \mathrm{C}\right)$ & $37.5 \pm 0.1$ & $37.5 \pm 0.1$ & $37.5 \pm 0.2$ \\
\hline \multicolumn{4}{|l|}{45 min after onset of ischemia } \\
\hline MAP (mmHg) & $91 \pm 21$ & $94 \pm 23$ & $102 \pm 12$ \\
\hline Arterial $\mathrm{pH}$ & $7.39 \pm 0.04$ & $7.40 \pm 0.05$ & $7.39 \pm 0.03$ \\
\hline $\mathrm{PaCO}_{2}(\mathrm{mmHg})$ & $40 \pm 5$ & $39 \pm 4$ & $40 \pm 3$ \\
\hline $\mathrm{PaO}_{2}(\mathrm{mmHg})$ & $200 \pm 36$ & $211 \pm 30$ & $209 \pm 33$ \\
\hline Pericranial temperature $\left({ }^{\circ} \mathrm{C}\right)$ & $37.6 \pm 0.1$ & $37.6 \pm 0.1$ & $37.6 \pm 0.1$ \\
\hline \multicolumn{4}{|c|}{$10 \mathrm{~min}$ after termination of ischemia } \\
\hline MAP (mmHg) & $76 \pm 21$ & $74 \pm 21$ & $66 \pm 11$ \\
\hline Arterial pH & $7.41 \pm 0.05$ & $7.43 \pm 0.05$ & $7.44 \pm 0.03$ \\
\hline $\mathrm{PaCO}_{2}(\mathrm{mmHg})$ & $38 \pm 5$ & $36 \pm 5$ & $34 \pm 4$ \\
\hline $\mathrm{PaO}_{2}(\mathrm{mmHg})$ & $194 \pm 21$ & $224 \pm 38$ & $213 \pm 25$ \\
\hline Pericranial temperature $\left({ }^{\circ} \mathrm{C}\right)$ & $37.6 \pm 0.1$ & $37.5 \pm 0.1$ & $37.5 \pm 0.1$ \\
\hline
\end{tabular}

All values are mean \pm SD. MAP, Mean arterial pressure; $\mathrm{PaCO}_{2}$, arterial carbon dioxide partial pressure; $\mathrm{PaO}$, arterial oxygen partial pressure. ${ }^{*} p<0.01$ versus vehicle group.

$31 \mathrm{~mm}^{3} ; p=0.03$ ), cortical (vehicle, $64 \pm 60 \mathrm{~mm}^{3}$; MnTE-2$\mathrm{PyP}^{5+}, 21 \pm 41 \mathrm{~mm}^{3} ; p=0.03$ ), and total (vehicle, $131 \pm 95 \mathrm{~mm}^{3}$; MnTE-2-PyP ${ }^{5+}, 60 \pm 68 \mathrm{~mm}^{3} ; p=0.02$ ) infarct volumes (Fig. 2).

In experiment $4, \mathrm{MnTE}^{2}-\mathrm{PyP}^{5+}$ or vehicle was given at $12 \mathrm{hr}$ after ischemia. There was no effect of MnTE-2-PyP ${ }^{5+}$ on neurologic scores (vehicle, $9 \pm 1$; MnTE-2-PyP ${ }^{5+}, 9 \pm 2 ; p=0.93$ ). Infarct size was not affected by MnTE-2-PyP ${ }^{5+}$ in cortex (vehicle, $46 \pm 48 \mathrm{~mm}^{3}$; MnTE-2-PyP $\left.{ }^{5+}, 33 \pm 41 \mathrm{~mm}^{3} ; p=0.45\right)$ or subcortex (vehicle, $57 \pm 32 \mathrm{~mm}^{3}$; MnTE-2-PyP ${ }^{5+}, 61 \pm 35 \mathrm{~mm}^{3}$; $p=0.76$ ). Total infarct volume was also similar between groups (vehicle, $103 \pm 78 \mathrm{~mm}^{3}$; MnTE-2-PyP ${ }^{5+}, 94 \pm 73 \mathrm{~mm}^{3} ; p=0.75$ ).

Figure 3 demonstrates the cumulative results for the different dosing intervals of MnTE-2-PyP ${ }^{5+}$ (experiments 1-4) depicting mean total infarct volume in treated animals as a fraction of mean total infarct volume in the respective vehicle-treated groups.
Intracerebroventricular administration of MnTE-2-PyP ${ }^{5+}$ was not found to have an effect on body temperature. Peritoneal temperature values (experiment 5) were similar between groups

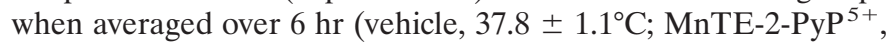
$37.6 \pm 1.0^{\circ} \mathrm{C}$ ) and $20 \mathrm{hr}$ (vehicle, $37.7 \pm 0.7^{\circ} \mathrm{C}$; MnTE-2-PyP ${ }^{5+}$, $\left.38.1 \pm 0.3^{\circ} \mathrm{C}\right)$ in rats given $\mathrm{MnTE}-2-\mathrm{PyP}^{5+}$ or vehicle $5 \mathrm{~min}$ after onset of reperfusion from $90 \mathrm{~min}$ MCAO.

\section{Experiments 6 and 7: protective effect of MnTE-2- $\mathrm{PyP}^{5+}$ correlates with decreased indices of oxidative stress in focal ischemia}

Physiologic values during experiments 6 and 7 were similar to the preceding experiments, and there were no differences between groups (data not shown).

Selective inactivation of mitochondrial aconitase, but not fu- 

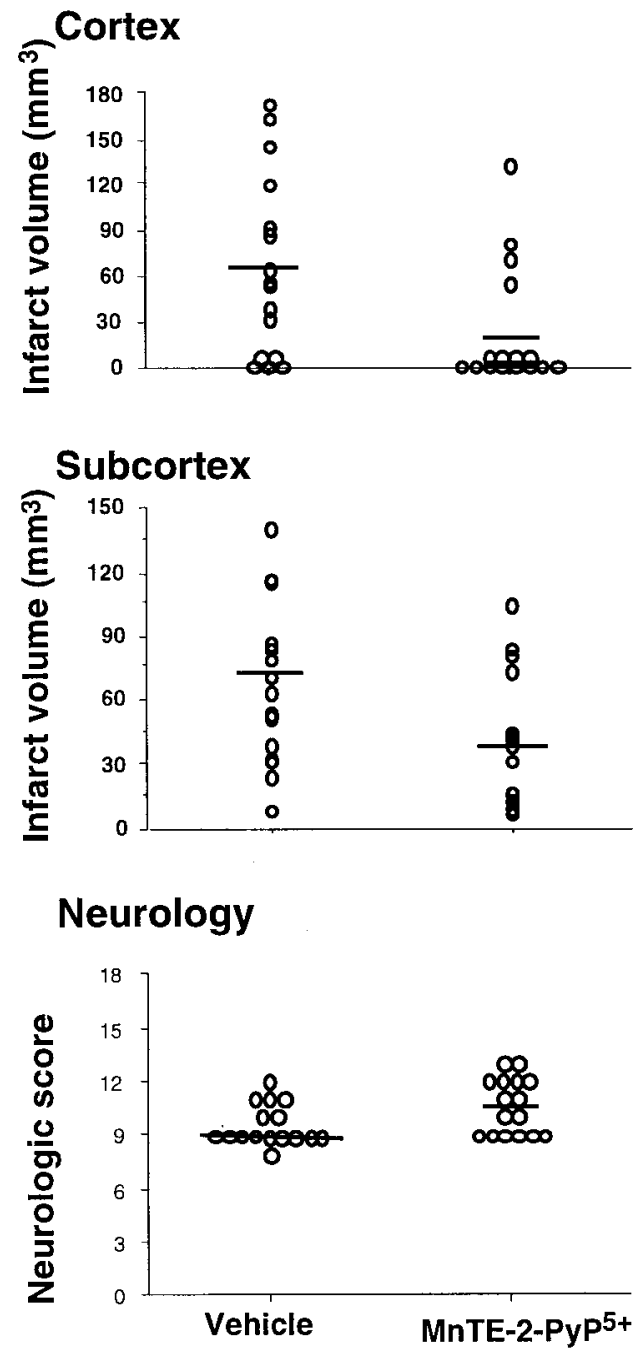

Figure 2. Protection by MnTE-2-PyP ${ }^{5+}$ when given $6 \mathrm{hr}$ after ischemia. Cerebral infarct volumes and neurologic scores were measured $7 \mathrm{~d}$ after a $90 \mathrm{~min}$ episode of transient middle cerebral artery occlusion. At $6 \mathrm{hr}$ after ischemia, MnTE-2-PyP ${ }^{5+}$ (300 ng) or vehicle was injected into the left lateral ventricle $\left(n=16\right.$ per group). MnTE-2-PyP ${ }^{5+}$ reduced infarct size (subcortex, $p=0.03$; cortex, $p=0.03$ ) and improved neurologic score $(18=$ normal $)(p=0.05)$. Open circles represent values for individual rats. Horizontal lines depict group mean values for infarct size and median values for neurologic score.

marase, was used as an index of superoxide production (Patel et al., 1996; Liang et al., 2000). In the initial analysis, we examined the effect of ischemia on aconitase and fumarase activities at 4 and $10 \mathrm{hr}$ after $90 \mathrm{~min}$ MCAO in rats treated with vehicle only. At $4 \mathrm{hr}$ after reperfusion, aconitase was selectively inactivated in the ischemic versus nonischemic hemisphere. Mammalian fumarase activity, previously shown to be resistant to oxidative stress in vitro (Patel et al., 1996), was unchanged by ischemia. At $10 \mathrm{hr}$ after ischemia, both aconitase and fumarase activity were reduced in the ischemic versus nonischemic hemisphere $(p<0.05)$. We then compared the enzymatic activities in the ischemic hemisphere as a function of MnTE-2-PyP ${ }^{5+}$ treatment. At 4 hr after ischemia, MnTE-2-PyP ${ }^{5+}$ that was given 5 min after reperfusion caused a $46 \%$ increase in aconitase activity versus vehicle-treated controls and had no effect on fumarase. At $10 \mathrm{hr}$ after ischemia, MnTE-2-PyP ${ }^{5+}$ that was given $6 \mathrm{hr}$ after reperfusion caused a 32

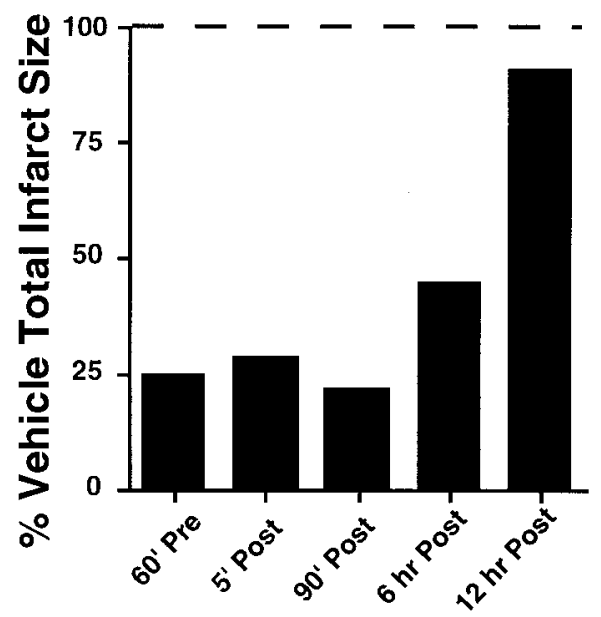

Treatment Interval

Figure 3. Mean total cerebral infarct volumes resulting from 90 min of middle cerebral artery occlusion and $7 \mathrm{~d}$ recovery in rats treated with intracerebroventricular MnTE-2-PyP ${ }^{5+}$ (300 ng; $n=13-16$ per group) as a percentage of mean total infarct volume in respective vehicle-treated controls. Values are given for the different treatment intervals studied in experiments $1-4$.

and $16 \%$ increase in aconitase and fumarase activities, respectively, versus values treated with vehicle (Fig. 4).

Superoxide is a precursor of more potent oxidants such as the hydroxyl radical, which can oxidatively damage cellular DNA. Consistent with this, ischemia increased the $8-\mathrm{OHdG} / \mathrm{dG}$ ratio approximately threefold when assessed at both 4 and $10 \mathrm{hr}$ after ischemia. There was no effect of MnTE-2-PyP ${ }^{5+}$ treatment on the $8-\mathrm{OHdG} / \mathrm{dG}$ ratio in the nonischemic hemisphere at either study interval. In the ischemic hemisphere, treatment with MnTE-2-PyP ${ }^{5+}$ reduced the $8-\mathrm{OHdG} / \mathrm{dG}$ ratio by $39 \%(p=$ $0.003)$ when given $5 \mathrm{~min}$ after reperfusion and by $21 \%(p=0.02)$ when given $6 \mathrm{hr}$ after ischemia. At both treatment intervals, however, the $8-\mathrm{OHdG} / \mathrm{dG}$ ratio in the ischemic hemisphere of MnTE-2-PyP ${ }^{5+}$-treated rats remained greater than that in the respective nonischemic hemisphere $(p<0.05)$ (Fig. 5).

\section{Experiment 8 (mouse focal ischemia-intravenous MnTE-2-PyP ${ }^{5+}$ after treatment)}

Recorded physiologic values are given in Table 3. There were no differences among groups. A main effect for treatment group on neurologic score was present (vehicle, $3 \pm 0.75$; MnTE-2-PyP $^{5+}$, $1 \mathrm{mg} / \mathrm{kg}, 3 \pm 2$; MnTE-2-PyP $\left.{ }^{5+}, 2 \mathrm{mg} / \mathrm{kg}, 2 \pm 2 ; p=0.04\right)$. Individual cerebral infarct volumes are given in Figure 6. Cortical infarct volume was reduced by MnTE-2-PyP ${ }^{5+}$ (vehicle, $46 \pm 16$ $\mathrm{mm}^{3}$; MnTE-2-PyP ${ }^{5+}, 1 \mathrm{mg} / \mathrm{kg}, 31 \pm 21 \mathrm{~mm}^{3}$; MnTE-2-PyP ${ }^{5+}$, $\left.2 \mathrm{mg} / \mathrm{kg}, 26 \pm 21 \mathrm{~mm}^{3} ; p=0.015\right)$. An intergroup difference was present for MnTE-2-PyP ${ }^{5+}(2 \mathrm{mg} / \mathrm{kg})$ versus vehicle $(p=0.017)$. Subcortical infarct volume was also reduced by MnTE-2-PyP (vehicle, $31 \pm 10 \mathrm{~mm}^{3}$; MnTE-2-PyP ${ }^{5+}, 1 \mathrm{mg} / \mathrm{kg}, 20 \pm 21 \mathrm{~mm}^{3}$; MnTE-2-PyP $\left.{ }^{5+}, 2 \mathrm{mg} / \mathrm{kg}, 15 \pm 12 \mathrm{~mm}^{3} ; p=0.013\right)$. Intergroup differences were present for both doses versus vehicle $(p<0.04)$. Total infarct volume was reduced by MnTE-2-PyP ${ }^{5+}$ (vehicle, $77 \pm 24 \mathrm{~mm}^{3}$; MnTE-2-PyP ${ }^{5+}, 1 \mathrm{mg} / \mathrm{kg}, 52 \pm 33 \mathrm{~mm}^{3}$; MnTE$\left.2-\mathrm{PyP}^{5+}, 2 \mathrm{mg} / \mathrm{kg}, 41 \pm 33 \mathrm{~mm}^{3} ; p=0.009\right)$. An intergroup difference was present for MnTE-2-PyP ${ }^{5+}(2 \mathrm{mg} / \mathrm{kg})$ versus vehicle $(p=0.006)$. 


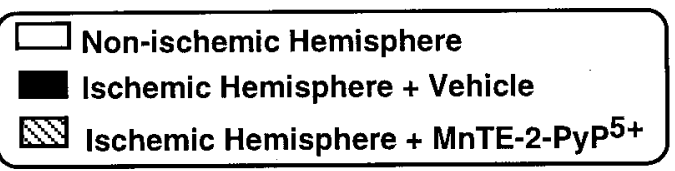

\section{Hrs Post-Ischemia}

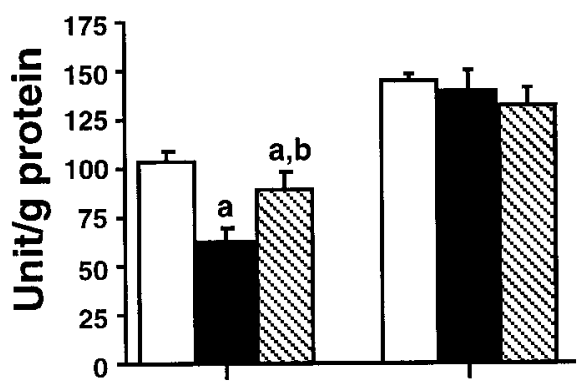

\section{Hrs Post-Ischemia}

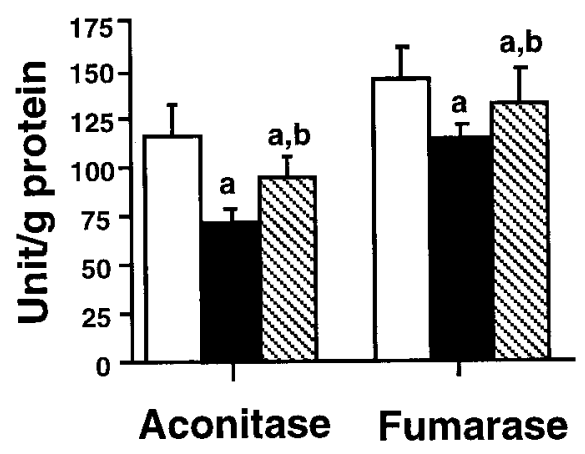

Figure 4. Effects of ischemia and $\mathrm{MnTE}-2-\mathrm{PyP}^{5+}$ on aconitase-fumarase activities. Rats were subjected to 90 min of middle cerebral artery occlusion and treated with intracerebroventricular vehicle or $300 \mathrm{ng}$ of MnTE-2-PyP ${ }^{5+}$ at $5 \mathrm{~min}$ or $6 \mathrm{hr}$ after onset of reperfusion. Brains were sampled at $4 \mathrm{hr}$ after treatment, respectively ( $n=6-8$ per condition). At $4 \mathrm{hr}$ after ischemia, aconitase was selectively decreased by ischemia in the vehicle-treated group. Aconitase activity was $47 \%$ greater in animals treated with MnTE-2-PyP ${ }^{5+}$. There was no effect of ischemia or MnTE$2-\mathrm{PyP}^{5+}$ on fumarase activity. At $10 \mathrm{hr}$ after ischemia, reductions in both aconitase and fumarase activities were observed. Both aconitase and fumarase activities were greater (32 and 16\%, respectively) in MnTE-2$\mathrm{PyP}^{5+}$ rats versus respective vehicle-treated controls. $a$, Difference from nonischemic hemisphere $(p<0.05)$; $b$, difference from ischemic hemisphere in vehicle-treated group $(p<0.05)$. Values represent mean $\pm \mathrm{SD}$.

\section{Experiment 9 (mouse focal ischemia-intraventricular MnTE-2-PyP ${ }^{5+}$ after treatment)}

Physiologic values were similar to those reported for experiment 8. Values were not different among groups (data not shown). A main effect for treatment group on neurologic scores was present (vehicle, $3 \pm 1$; MnTE-2-PyP ${ }^{5+}, 50$ ng, $3 \pm 1$; MnTE-2-PyP $^{5+}$, $100 \mathrm{ng}, 2 \pm 2 ; p=0.007)$. Cortical infarct volume was reduced by MnTE-2-PyP ${ }^{5+}$ (vehicle, $42 \pm 8 \mathrm{~mm}^{3}$; MnTE-2-PyP ${ }^{5+}, 50 \mathrm{ng}$, $29 \pm 12 \mathrm{~mm}^{3}$; MnTE-2-PyP $\left.{ }^{5+}, 100 \mathrm{ng}, 28 \pm 16 \mathrm{~mm}^{3} ; p=0.008\right)$. Intergroup differences were present for both doses versus vehicle $(p<0.04)$. Subcortical infarct volume was also reduced by MnTE-2-PyP ${ }^{5+}$ (vehicle, $28 \pm 8 \mathrm{~mm}^{3}$; MnTE-2-PyP ${ }^{5+}, 50 \mathrm{ng}$, $20 \pm 10 \mathrm{~mm}^{3}$; MnTE-2-PyP $\left.{ }^{5+}, 100 \mathrm{ng}, 20 \pm 10 \mathrm{~mm}^{3} ; p=0.03\right)$. Total infarct volume was reduced by MnTE-2- $\mathrm{PyP}^{5+}$ (vehicle, $70 \pm 25 \mathrm{~mm}^{3}$; MnTE-2-PyP ${ }^{5+}, 50 \mathrm{ng}, 50 \pm 20 \mathrm{~mm}^{3}$; MnTE-2$\left.\mathrm{PyP}^{5+}, 100 \mathrm{ng}, 48 \pm 25 \mathrm{~mm}^{3} ; p=0.009\right)$. Intergroup differences were present for both doses versus vehicle $(p<0.04)$.

\section{Non-ischemic Hemisphere Ischemic Hemisphere}

\section{Hrs Post-Ischemia}

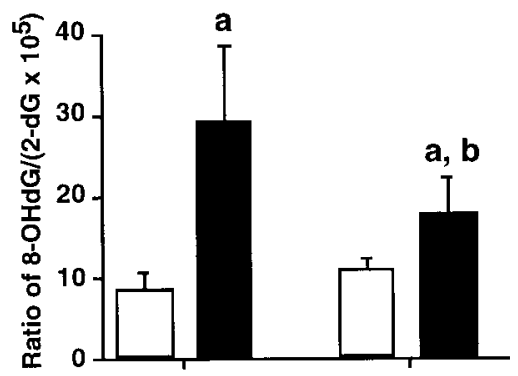

\section{Hrs Post-Ischemia}

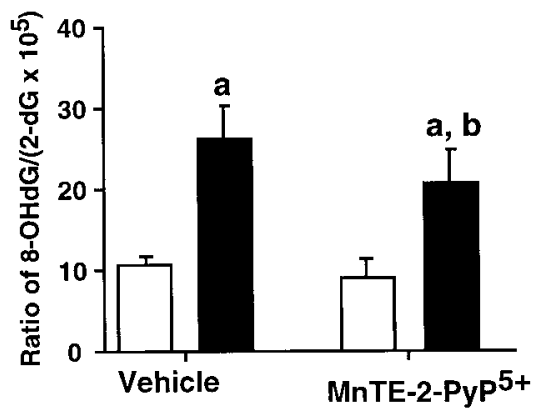

Figure 5. Ischemia-induced oxidation of DNA and protection by MnTE2-PyP ${ }^{5+}$. Rats were treated with intracerebroventricular MnTE-2-PyP ${ }^{5+}$ $(300 \mathrm{ng})$ or vehicle at $5 \mathrm{~min}$ or $6 \mathrm{hr}$ after onset of reperfusion from $90 \mathrm{~min}$ middle cerebral artery occlusion ( $n=6-8$ per condition). Brains were sampled at $4 \mathrm{hr}$ after treatment, respectively $(n=6-8$ per condition). The ratio of 8 -hydroxy-2'-deoxyguanosine $(8-O H d G)$ to 2 '-deoxyguanosine $(d G)$ was determined in cortical tissue $4 \mathrm{hr}$ after drug-vehicle treatment. There was no effect of MnTE-2-PyP ${ }^{5+}$ in the nonischemic hemisphere at either study interval. Ischemia increased the $8-\mathrm{OHdG} / \mathrm{dG}$ ratio nearly threefold at $4 \mathrm{hr}$, and this persisted at $10 \mathrm{hr}$ after ischemia (see vehicletreated groups). Treatment with MnTE-2-PyP ${ }^{5+}$ reduced the ischemic $8-\mathrm{OHdG} / \mathrm{dG}$ ratio by $39 \%(p=0.003)$ when given $5 \mathrm{~min}$ after reperfusion and by $21 \%$ when given $6 \mathrm{hr}$ after ischemia. At both treatment intervals, the ratio in the ischemic hemisphere of MnTE-2-PyP ${ }^{5+}$-treated rats remained greater than in the respective nonischemic hemisphere. $a$, Difference between ischemic and nonischemic hemisphere $(p \leq 0.02) ; b$, difference between treatment vehicle and MnTE-2-PyP ${ }^{5+}$ groups in the ischemic hemisphere $(p<0.05)$. Values represent mean \pm SD.

\section{Experiment 10: MnTE-2-PyP ${ }^{5+}$ is not effective in preventing near-complete forebrain ischemia-induced selective neuronal necrosis}

Physiologic values are summarized in Table 4. There were no significant differences among groups. Five days after ischemia, hippocampal CA1 injury was similar among groups (vehicle, $70 \pm$ $33 \%$ dead neurons; MnTE-2-PyP ${ }^{5+}, 150 \mathrm{ng}, 77 \pm 33 \%$ dead neurons; MnTE-2-PyP ${ }^{5+}, 300$ ng, $67 \pm 34 \%$ dead neurons; $p=$ 0.594). Damage in the cortex (vehicle, $1 \pm 1$; MnTE-2-PyP ${ }^{5+}, 150$ ng, $1 \pm 1$; MnTE-2-PyP $\left.{ }^{5+}, 300 \mathrm{ng}, 0 \pm 1 ; p=0.839\right)$ and caudoputamen (vehicle, $2 \pm 1$; MnTE-2-PyP ${ }^{5+}, 150 \mathrm{ng}, 2 \pm 1$; MnTE-2-PyP ${ }^{5+}, 300 \mathrm{ng}, 2 \pm 1 ; p=0.862$ ) was not different among groups. Total motor score values were $8 \pm 2$ in all three groups.

\section{DISCUSSION}

The synthetic porphyrin catalytic antioxidant, MnTE-2-PyP ${ }^{5+}$, caused major reduction of ischemic brain damage when admin- 


\begin{tabular}{|c|c|c|c|}
\hline & $\begin{array}{l}\text { Vehicle } \\
(n=15)\end{array}$ & $\begin{array}{l}\text { MnTE-2-PyP }{ }^{5+} \\
1 \mathrm{mg}(n=17)\end{array}$ & $\begin{array}{l}\text { MnTE-2-PyP }{ }^{5+} \\
2 \mathrm{mg}(n=18)\end{array}$ \\
\hline Preischemia body weight (gm) & $22 \pm 1$ & $22 \pm 1$ & $23 \pm 1$ \\
\hline Day 1 body weight (gm) & $21 \pm 1$ & $21 \pm 1$ & $21 \pm 1$ \\
\hline \multicolumn{4}{|l|}{$10 \mathrm{~min}$ before ischemia } \\
\hline MAP (mmHg) & $78 \pm 5$ & $80 \pm 5$ & $78 \pm 6$ \\
\hline Arterial $\mathrm{pH}$ & $7.19 \pm 0.06$ & $7.20 \pm 0.04$ & $7.19 \pm 0.04$ \\
\hline $\mathrm{PaCO}_{2}(\mathrm{mmHg})$ & $37 \pm 3$ & $36 \pm 3$ & $37 \pm 3$ \\
\hline $\mathrm{PaO}_{2}(\mathrm{mmHg})$ & $189 \pm 27$ & $183 \pm 30$ & $176 \pm 28$ \\
\hline Pericranial temperature $\left({ }^{\circ} \mathrm{C}\right)$ & $37.0 \pm 0.1$ & $37.0 \pm 0.1$ & $37.0 \pm 0.1$ \\
\hline \multicolumn{4}{|l|}{25 min after onset of ischemia } \\
\hline MAP (mmHg) & $74 \pm 6$ & $76 \pm 5$ & $75 \pm 6$ \\
\hline Pericranial temperature $\left({ }^{\circ} \mathrm{C}\right)$ & $37.0 \pm 0.1$ & $37.0 \pm 0.2$ & $37.0 \pm 0.1$ \\
\hline \multicolumn{4}{|c|}{$10 \mathrm{~min}$ after termination of ischemia } \\
\hline MAP (mmHg) & $71 \pm 5$ & $72 \pm 5$ & $73 \pm 5$ \\
\hline Pericranial temperature $\left({ }^{\circ} \mathrm{C}\right)$ & $37.0 \pm 0.1$ & $37.0 \pm 0.1$ & $37.0 \pm 0.1$ \\
\hline
\end{tabular}

All values are mean \pm SD. MAP, Mean arterial pressure; $\mathrm{PaCO}_{2}$, arterial carbon dioxide partial pressure; $\mathrm{PaO}$, arterial oxygen partial pressure. There were no differences among groups.

\begin{tabular}{|c|c|c|c|}
\hline & $\begin{array}{l}\text { Vehicle } \\
(n=23)\end{array}$ & $\begin{array}{l}\text { MnTE-2-PyP }{ }^{5+} \\
150 \text { ng }(n=20)\end{array}$ & $\begin{array}{l}\text { MnTE-2-PyP }{ }^{5+} \\
300 \mathrm{ng}(n=20)\end{array}$ \\
\hline Preischemia body weight (gm) & $288 \pm 13$ & $288 \pm 12$ & $297 \pm 16$ \\
\hline Day 5 body weight (gm) & $304 \pm 20$ & $306 \pm 19$ & $308 \pm 24$ \\
\hline \multicolumn{4}{|l|}{$10 \mathrm{~min}$ before ischemia } \\
\hline MAP (mmHg) & $85 \pm 19$ & $86 \pm 20$ & $92 \pm 18$ \\
\hline Arterial $\mathrm{pH}$ & $7.41 \pm 0.04$ & $7.39 \pm 0.05$ & $7.40 \pm 0.03$ \\
\hline $\mathrm{PaCO}_{2}(\mathrm{mmHg})$ & $37 \pm 2$ & $38 \pm 4$ & $37 \pm 2$ \\
\hline $\mathrm{PaO}_{2}(\mathrm{mmHg})$ & $162 \pm 25$ & $174 \pm 35$ & $173 \pm 31$ \\
\hline Glucose (mg/dl) & $111 \pm 8$ & $105 \pm 12$ & $114 \pm 17$ \\
\hline Hematocrit $(\%)$ & $42 \pm 2$ & $42 \pm 2$ & $42 \pm 2$ \\
\hline Pericranial temperature $\left({ }^{\circ} \mathrm{C}\right)$ & $37.4 \pm 0.3$ & $37.5 \pm 0.2$ & $37.4 \pm 0.3$ \\
\hline \multicolumn{4}{|c|}{10 min after termination of ischemia } \\
\hline MAP (mmHg) & $109 \pm 11$ & $112 \pm 14$ & $111 \pm 8$ \\
\hline Arterial pH & $7.31 \pm 0.09$ & $7.31 \pm 0.07$ & $7.28 \pm 0.08$ \\
\hline $\mathrm{PaCO}_{2}(\mathrm{mmHg})$ & $41 \pm 4$ & $40 \pm 3$ & $42 \pm 4$ \\
\hline $\mathrm{PaO}_{2}(\mathrm{mmHg})$ & $187 \pm 26$ & $197 \pm 33$ & $198 \pm 33$ \\
\hline Pericranial temperature $\left({ }^{\circ} \mathrm{C}\right)$ & $37.5 \pm 0.1$ & $37.4 \pm 0.3$ & $37.4 \pm 0.2$ \\
\hline
\end{tabular}

All values are mean \pm SD. MAP, Mean arterial pressure; $\mathrm{PaCO}_{2}$, arterial carbon dioxide partial pressure; $\mathrm{PaO}$, arterial oxygen partial pressure. There were no differences among groups.

istered in a single dose 60 min before onset of MCAO or up to 6 hr after onset of reperfusion. This benefit was evident both histologically and neurologically in rats allowed to survive $7 \mathrm{~d}$ after the ischemic insult. MnTE-2-PyP ${ }^{5+}$ also reduced cerebral infarct size and improved neurologic function when given intravenously or intracerebroventricularly after reperfusion from transient MCAO in the mouse. MnTE-2-PyP ${ }^{5+}$ preserved rat mitochondrial aconitase activity and reduced DNA oxidation when given 5 min or $6 \mathrm{hr}$ after ischemia but had no effect on body temperature. In contrast, MnTE-2-PyP ${ }^{5+}$ had no effect on rat selective neuronal necrosis resulting from near-complete forebrain ischemia.

MnTE-2-PyP ${ }^{5+}$ was chosen for study from a family of metalloporphyrins. Cationic ortho $N$-ethylpyridyl groups on the me- thine bridge carbons of the porphyrin ring system provide electrostatic guidance for $\mathrm{O}_{\dot{2}}^{-}$. The resulting nonplanarity diminishes the interaction of MnTE-2-PyP ${ }^{5+}$ with DNA. Furthermore, close proximity of the positively charged groups to the manganese metal center of this ortho isomer, when compared with the para isomer, shifts the metal-redox potential to a more positive value (Batinić-Haberle et al., 1999; Spasojevic and Batinić-Haberle, 2001). Thus the redox potential of the ortho isomer is $+0.23 \mathrm{~V}$ as opposed to the para isomer $(+0.06 \mathrm{~V})$ versus normal hydrogen electrode. Both of these effects, steric and electronic, make for a powerful catalytic antioxidant that is 20 times more active in dismuting $\mathrm{O}_{2}^{-}$than the para analog (Batinić-Haberle et al., 1998). Studies with SOD-deficient Escherichia coli demonstrate that $25 \mu \mathrm{M}$ of the ortho isomer greatly facilitates growth, whereas 


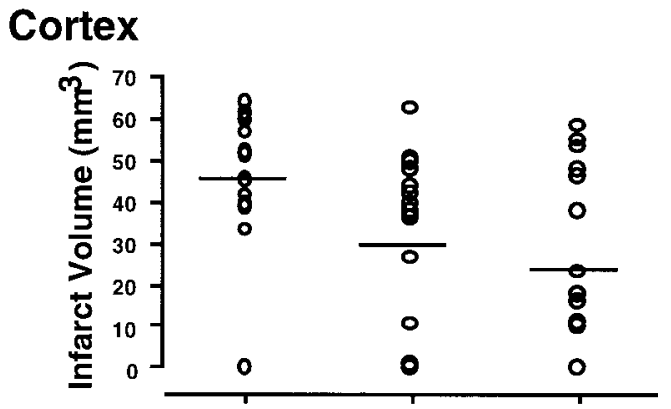

Subcortex
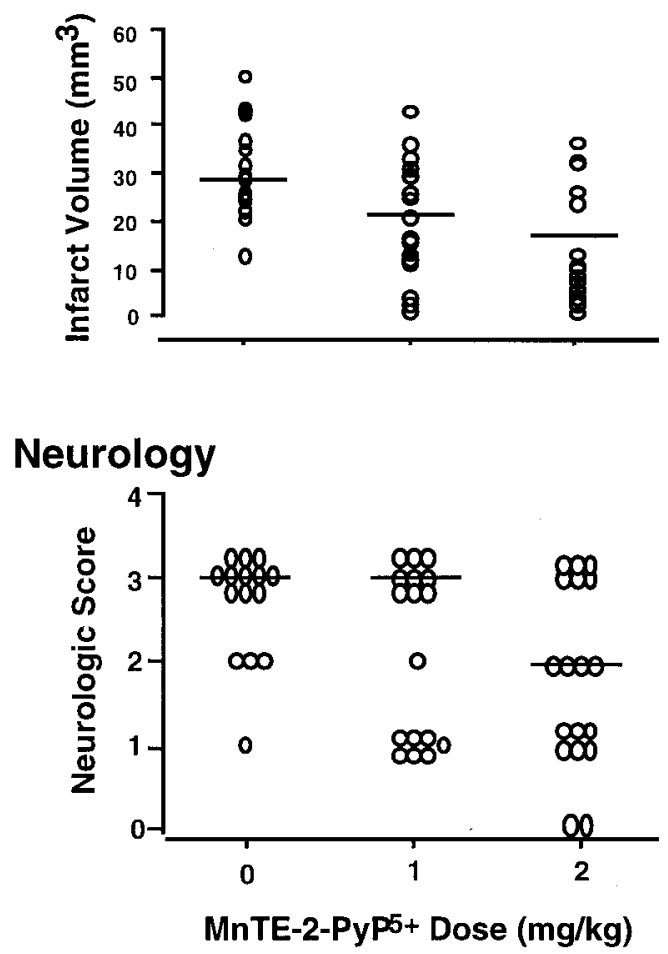

Figure 6. Mice were subjected to $90 \mathrm{~min}$ of middle cerebral artery occlusion. Five minutes after onset of reperfusion, $0 \mathrm{mg} / \mathrm{kg}(n=15), 1$ $\mathrm{mg} / \mathrm{kg}(n=17)$, or $2 \mathrm{mg} / \mathrm{kg}(n=18) \mathrm{MnTE}^{2}-\mathrm{PyP}^{5+}$ (in PBS vehicle, total injectate volume $=15 \mu \mathrm{l}$ ) was injected intravenously. Infarct volumes for individual mice (open circles) measured at $24 \mathrm{hr}$ after ischemia are shown. Horizontal bars indicate group mean values. Top, Cortical infarct volume was reduced by MnTE-2-PyP ${ }^{5+}(p=0.015)$. An intergroup difference was present for MnTE-2-PyP ${ }^{5+}(2 \mathrm{mg} / \mathrm{kg})$ versus vehicle $(p=0.017)$. Middle, Subcortical infarct volume was also reduced by MnTE-2-PyP ${ }^{5+}(p=0.013)$. Intergroup differences were present for both doses versus vehicle $(p<0.04)$. Total infarct volume was reduced by MnTE-2-PyP ${ }^{5+}(p=0.009)$. An intergroup difference was present for MnTE-2-PyP ${ }^{5+}(2 \mathrm{mg} / \mathrm{kg})$ versus vehicle $(p=0.006)$. Bottom, Neurologic scores for individual mice are depicted $(0$, normal; 4 , cannot walk spontaneously). Horizontal bars indicate group median values. A main effect for treatment group was present $(p=0.04)$.

the para compound is toxic at this level (Batinić-Haberle et al., 1998).

MnTE-2-PyP ${ }^{5+}$ has five positive charges. This may limit significant transfer across the blood-brain barrier and into the cell. We therefore chose to first study intracerebroventricular MnTE$2-\mathrm{PyP}^{5+}$ injection. An initial dose of $1 \mu \mathrm{g}$ was given. Within 1-2 min after injection, all rats exhibited hindlimb abduction, body and head tremor, ataxia, vertical jumping, tactile hyperreactivity, and proptosis. We progressively decreased the MnTE-2-PyP ${ }^{5+}$ dose to $300 \mathrm{ng}$, which resulted in complete absence of the above effects. Accordingly, 300 and $150 \mathrm{ng}$ were examined in the MCAO model. Because there was little difference in histologic-neurologic outcome in rats given these two doses of $\mathrm{MnTE}^{-2}-\mathrm{PyP}^{5+}$, we believe that an efficacious therapeutic dose may be $<150 \mathrm{ng}$. In addition, some indication of the duration of action of intracerebroventricular MnTE-2-PyP ${ }^{5+}$ was obtained. The behavioral side effects associated with $1 \mu \mathrm{g}$ of MnTE-2-PyP persisted for 6-8 hr, after which animals recovered to normal behavior.

During pilot studies, intravenous administration of a single bolus of $1 \mathrm{mg}$ of MnTE-2-PyP ${ }^{5+}$ in the rat did not produce the behavioral effects described above. However, substantial reduction in blood pressure was observed. This effect was absent in the mouse. We therefore examined efficacy of $\mathrm{MnTE}^{-2-\mathrm{PyP}^{5+}}$ that was given intravenously in a mouse model of temporary MCAO in which confounds from systemic hypotension would be absent. Again, substantial reduction in infarct size and improvement in neurologic scores were observed.

The fact that administration of a catalytic antioxidant provides substantial neuroprotection as late as $6 \mathrm{hr}$ after ischemia calls into question the source of $\mathrm{O}_{2}^{-}$this late after onset of reperfusion. A principle source of ischemia-induced $\mathrm{O}_{2}^{-}$is the mitochondria (Piantadosi and Zhang, 1996). Selective inactivation of aconitase by increased $\mathrm{O}_{2}^{-}$is consistent with this. Ischemia and/or reperfusion also result in chemotactic recruitment and activation of neutrophils that synthesize and release $\mathrm{O}_{2}^{-}$at a high rate (Hoffstein et al., 1985; Kochanek and Hallenbeck, 1992). Recruitment of neutrophils occurs within the first few hours after ischemia and/or reperfusion (Clark et al., 1994; Zhang et al., 1994). Activation of microglia by cytokines also results in $\mathrm{O}_{2}^{-}$release (Sankarapandi et al., 1998). Activation of microglia has been shown to begin within the first few minutes after onset of ischemia and to persist for hours (Ivacko et al., 1996; Rupalla et al., 1998). $\mathrm{O}_{\dot{2}}^{-}$can also be derived from membrane-bound cyclooxygenase-2 (COX-2), phospholipase A, and NADPH-oxidase. Upregulation of some of these enzymes during ischemia and/or reperfusion has been documented (Gajkowska and Mossakowski, 1997). Examination of the temporal course of these events in experimental paradigms in which MnTE-2-PyP ${ }^{5+}$ is administered may provide insight into the relative importance of these factors with respect to ischemic outcome. It is also clear that effects of MnTE-2-PyP ${ }^{5+}$ extend into the intracellular compartment, based on our finding that mitochondrial aconitase activity, an enzyme in the tricarboxylic acid cycle with known sensitivity to $\mathrm{O}_{2}^{-}$(Gardner and Fridovich, 1992; Liang et al., 2000), was preserved in treated animals.

MnTE-2-PyP ${ }^{5+}$ was also shown to reduce oxidative stress, as defined by the $8-\mathrm{OHdG} / \mathrm{dG}$ ratios, when given at $5 \mathrm{~min}$ after onset of reperfusion. Given the exquisite sensitivity of mitochondrial DNA to oxidative damage, it is tempting to speculate that a large part of the 8-OHdG signal may have been mitochondrial in origin. However, when MnTE-2-PyP ${ }^{5+}$ was given at $6 \mathrm{hr}$ after reperfusion, a $54 \%$ reduction in ischemic injury was still observed. This suggests that oxidative injury occurring in the first few hours after MCAO is not of singular importance to outcome as defined at $7 \mathrm{~d}$ after ischemia. When treatment was initiated $6 \mathrm{hr}$ after reperfusion, the mimetic was still $76 \%$ as effective as when given at 5 min after ischemia. However, assessment of aconitase-fumarase activities, serving as indicators of increased $\mathrm{O}_{2}^{-}$production, revealed a different pattern when MnTE-2-PyP ${ }^{5+}$ was given $6 \mathrm{hr}$ as op- 
posed to $5 \mathrm{~min}$ after ischemia. In vehicle-treated animals, aconitase activity was reduced by ischemia when measured at both 4 and $10 \mathrm{hr}$ after ischemia, and this was, in part, preserved by MnTE-2-PyP ${ }^{5+}$ whether it was given at $5 \mathrm{~min}$ or $6 \mathrm{hr}$ after ischemia. In contrast, at $4 \mathrm{hr}$ after ischemia, fumarase activity was not altered by ischemia, whereas it was reduced at $10 \mathrm{hr}$ after ischemia. Fumarase is largely resistant to direct oxidative injury by $\mathrm{O}_{2}^{-}$(Liang et al., 2000; Patel et al., 1996). Therefore, decay in its activity at $10 \mathrm{hr}$ suggests general mitochondrial dysfunction and cell death.

MnTE-2-PyP ${ }^{5+}$ partially preserved fumarase activity when given at $6 \mathrm{hr}$ after ischemia, indicating that the compound protected at late administration intervals by less specific mechanisms than $\mathrm{O}_{2}^{-}$scavenging alone. For example, if delayed inflammatory mechanisms invoked by ischemia produce $\mathrm{O}_{2}^{-}$that in turn reacts with nitric oxide to yield peroxynitrite, treatment with spin trap molecules (e.g., NXY-509) that show preference to hydroxyl radical would not be as effective in reducing injury (Kuroda et al., 1999). In contrast, MnTE-2-PyP ${ }^{5+}$ is highly reactive with $\mathrm{O}_{2}^{-}$and also possesses potential to react with both nitric oxide (Spasojevic et al., 2000) and peroxynitrite (Ferrer-Sueta et al., 1999). This may explain its unique efficacy when given $6 \mathrm{hr}$ after reperfusion. Delayed efficacy is also consistent with work using transgenic mice in which targeted deletion of either COX-2 or inducible nitric oxide synthase (iNOS) was performed (Iadecola et al., 1997; Nogawa et al., 1997). In those studies, cerebral infarct sizes resulting from focal ischemia were reduced. Because induction of COX-2 and iNOS was not seen in wild-type mice for many hours after ischemia onset, those studies provide evidence that delayed inflammatory events can contribute substantially to final lesion size.

MnTE-2-PyP ${ }^{5+}$ failed to alter selective neuronal necrosis resulting from near-complete forebrain ischemia. This came as a surprise, given reports that some free radical scavengers and catalytic antioxidants provide outcome efficacy in temperaturecontrolled models of global ischemia (Yamamoto et al., 1997; Soehle et al., 1998; Lipton, 1999). In addition, overexpression of $\mathrm{Cu}, \mathrm{Zn}-\mathrm{SOD}$ and EC-SOD causes reduced injury in mice subjected to global ischemia (Murakami et al., 1997; Sheng et al., 2000). We cannot explain the discrepancy of results with MnTE$2-\mathrm{PyP}^{5+}$ given current data. There are numerous inherent differences in the pathophysiology of global and focal ischemia. Focal ischemia presents an ischemic penumbra with graded blood flow (Ginsberg and Pulsinelli, 1994), spontaneous depolarizations (Nedergaard and Hansen, 1993), and a greater proclivity to neutrophil recruitment (Hayward et al., 1996) that may in part explain greater sensitivity to MnTE-2-PyP ${ }^{+}$. It is unlikely, however, that lack of effects in global ischemia is attributable to MnTE-2-PyP ${ }^{+}$effects on intraischemic blood flow. The twovessel occlusion model used in our laboratory consistently causes intraischemic blood flow to be reduced to autoradiographically undetectable levels in rats that are given anesthetics having marked differences in effects on cerebral blood flow (Mackensen et al., 2000). Furthermore, overexpression of EC-SOD does not alter intraischemic or early reperfusion blood flow values (Sheng et al., 2000).

In conclusion, intrathecal administration of the porphyrinbased catalytic antioxidant, MnTE-2- $\mathrm{PyP}^{5+}$, caused marked reduction of focal ischemic brain injury when given as late as $6 \mathrm{hr}$ after onset of reperfusion. Pharmacologic characteristics of the compound require further definition. However, efficacy of delayed administration of an antioxidant is consistent with recent evidence that production of reactive oxygen species is sustained for substantial intervals after ischemia and provides a rational therapeutic strategy for intervention.

\section{REFERENCES}

Arashidani K, Iwamoto-Tanaka N, Muraoka M, Kasai H (1998) Genotoxicity of ribo- and deoxyribonuclosides of 8-hydroxyguanine 5-hydroxycytosine and 2-hydroxyadenine: induction of SCE in human lymphocytes and mutagenicity in Salmonella typhirium TA100. Mutat Res 403:223-227.

Batinić-Haberle I (2001) Manganese porphyrins and related compounds. Meth Enzymol, in press.

Batinić-Haberle I, Liochev SI, Spasojevic I, Fridovich I (1997) A potent superoxide dismutase mimic: manganese $\beta$-octabromo meso-tetrakis$(N$-methylpyridinium-4-yl) porphyrin. Arch Biochem Biophys 343:225-233.

Batinić-Haberle I, Benov L, Spasojevic I, Fridovich I (1998) The ortho effect makes manganese(III) meso-tetrakis ( $N$-methylpyridinium-2-yl) porphyrin (MnTM-2-PyP 5+) a powerful and potentially useful superoxide dismutase mimic. J Biol Chem 273:24521-24528.

Batinić-Haberle I, Spasojevic I, Hambright P, Benov L, Crumbliss AL, Fridovich I (1999) Relationship among redox potentials, proton dissociation constants of pyrrolic nitrogens, and in vivo and in vitro superoxide dismutating activities of manganese(III) and iron(III) watersoluble porphyrins. Inorg Chem 38:4011-4022.

Belayev L, Alonso OF, Busto R, Zhao WZ, Ginsberg MD (1996) Middle cerebral artery occlusion in the rat by intraluminal suture. Neurological and pathological evaluation of an improved model. Stroke 27: $1616-1622$.

Clark RK, Lee EV, White RF, Jonak ZL, Feuerstein GZ, Barone FC (1994) Reperfusion following focal stroke hastens inflammation and resolution of ischemic injured tissue. Brain Res Bull 35:387-392.

Coimbra C, Drake M, Boris-Moller F, Wieloch T (1996) Long-lasting neuroprotective effect of postischemic hypothermia and treatment with an anti-inflammatory/antipyretic drug. Evidence for chronic encephalopathic processes following ischemia. Stroke 27:1578-1584.

Combs DJ, D'Alecy LG (1987) Motor performance in rats exposed to severe forebrain ischemia: effect of fasting and 1,3-butanediol. Stroke 18:503-511.

Day BJ, Fridovich I, Crapo JD (1997) Manganic porphyrins possess catalase activity and protect endothelial cells against hydrogen peroxide-mediated injury. Arch Biochem Biophys 347:256-262.

Day BJ, Batinić-Haberle I, Crapo JD (1999) Metalloporphyrins are potent inhibitors of lipid peroxidation. Free Radic Biol Med 26:730-736.

Fabian RH, DeWitt DS, Kent TA (1995) In vivo detection of superoxide anion production by the brain using a cytochrome $\mathrm{c}$ electrode. J Cereb Blood Flow Metab 15:242-247.

Ferrer-Sueta G, Batinić-Haberle I, Spasojevic I, Fridovich I, Radi R (1999) Catalytic scavenging of peroxynitrite by isomeric Mn(III) $\mathrm{N}$-methylpyridylporphyrins in the presence of reductants. Chem Res Toxicol 12:442-449.

Forsman M, Fleischer J, Milde J, Steen P, Michenfelder JD (1988) Superoxide dismutase and catalase failed to improve neurologic outcome after complete cerebral ischemia in the dog. Acta Anaesthesiol Scand 32:152-155.

Gajkowska B, Mossakowski MJ (1997) Endothelial nitric oxide synthase in vascular endothelium of rat hippocampus after ischemia: evidence and significance. Folia Neuropathol 35:171-180.

Garcia JH, Wagner S, Liu KF, Hu XJ (1995) Neurological deficit and extent of neuronal necrosis attributable to middle cerebral artery occlusion in rats: statistical validation. Stroke 26:627-635.

Gardner PR, Fridovich I (1992) Inactivation-reactivation of aconitase in Escherichia coli. A sensitive measure of superoxide radical. J Biol Chem 267:8757-8763.

Ginsberg MD, Pulsinelli WA (1994) The ischemic penumbra, injury thresholds, and the therapeutic window for acute stroke. Ann Neurol 36:553-554.

Gionet TX, Thomas JD, Warner DS, Goodlett CR, Wasserman EA, West JR (1991) Forebrain ischemia induces selective behavioral impairments associated with hippocampal injury in rats. Stroke 22:1040-1047.

Gionet TX, Warner DS, Verhaegen M, Thomas JD, Todd MM (1992) Effects of intra-ischemic blood pressure on outcome from 2-vessel occlusion forebrain ischemia in the rat. Brain Res 586:188-194.

Globus MYT, Busto R, Lin B, Schnippering H, Ginsberg MD (1995a) Detection of free radical activity during transient global ischemia and recirculation: effects of intraischemic brain temperature modulation. J Neurochem 65:1250-1256.

Globus MYT, Alonso O, Dietrich WD, Busto R, Ginsberg MD (1995b) Glutamate release and free radical production following brain injury: effects of posttraumatic hypothermia. J Neurochem 65:1704-1712.

Haun SE, Kirsch JR, Helfaer MA, Kubos KL (1991) Polyethylene glycol conjugated superoxide dismutase fails to augment brain superoxide dismutase activity in piglets. Stroke 22:658-659. 
Hayward NJ, Elliott PJ, Sawyer SD, Bronson RT, Bartus RT (1996) Lack of evidence for neutrophil participation during infarct formation following focal cerebral ischemia in the rat. Exp Neurol 139:188-202.

Hoffstein ST, Gennaro DE, Manzi RM (1985) Neutrophils may directly synthesize both $\mathrm{H}_{2} \mathrm{O}_{2}$ and $\mathrm{O}_{2}$ - since surface stimuli induce their release in stimulus-specific ratios. Inflammation 9:425-437.

Iadecola C, Zhang F, Casey R, Nagayama M, Ross ME (1997) Delayed reduction of ischemic brain injury and neurological deficits in mice lacking the inducible nitric oxide synthase gene. J Neurosci 17:9157-9164.

Ivacko JA, Sun R, Silverstein FS (1996) Hypoxic-ischemic brain injury induces an acute microglial reaction in perinatal rats. Pediatr Res 39:39-47.

Kasai H, Crain PF, Kuchino Y, Nishimura S, Ootsuyama A, Tanooka H (1986) Formation of 8-hydroxyguanine moiety in cellular DNA by agents producing oxygen radicals and evidence for its repair. Carcinogenesis 7:1849-1851.

Kochanek PM, Hallenbeck JM (1992) Polymorphonuclear leukocytes and monocytes/macrophages in the pathogenesis of cerebral ischemia and stroke. Stroke 23:1367-1379.

Kondo T, Reaume AG, Huang TT, Carlson E, Murakami K, Chen SF, Hoffman EK, Scott RW, Epstein CJ, Chan PH (1997) Reduction of $\mathrm{CuZn}$-superoxide dismutase activity exacerbates neuronal cell injury and edema formation after transient focal cerebral ischemia. J Neurosci 17:4180-4189.

Kontos HA, Wei EP (1986) Superoxide production in experimental brain injury. J Neurosurg 64:803-807.

Krebs HA, Holzach O (1952) The conversion of citrate into cisaconitate and isocitrate in the presence of aconitase. Biochem $\mathrm{J}$ 52:527-528.

Kuroda S, Tsuchidate R, Smith ML, Maples KR, Siesjo BK (1999) Neuroprotective effects of a novel nitrone, NXY-059, after transient focal cerebral ischemia in the rat. J Cereb Blood Flow Metab 19:778-787.

Lawrence GD, Sawyer DT (1979) Potentiometric titrations and oxidation-reduction potentials of manganese and copper-zinc superoxide dismutases. Biochemistry 18:3045-3050.

Liang LP, Ho YS, Patel MN (2000) Mitochondrial superoxide production in kainate-induced hippocampal damage. Neuroscience 101: $563-570$.

Lipton P (1999) Ischemic cell death in brain neurons. Physiol Rev 79:1431-1568.

Mackensen GB, Nellgård B, Kudo M, Sheng H, Pearlstein RD, Warner DS (2000) Periischemic cerebral blood flow does not explain beneficial effects of isoflurane on outcome from near-complete forebrain ischemia in rats. Anesthesiology 93:1101-1106.

Matsumiya N, Koehler RC, Kirsch JR, Traystman RJ (1991) Conjugated superoxide dismutase reduces extent of caudate injury after transient focal ischemia in cats. Stroke 22:1193-1200.

McCord JM, Fridovich I (1969) Superoxide dismutase: an enzymatic function for erythrocuprein (hemocuprein). J Biol Chem 244: 6049-6055.

Mikawa S, Kinouchi H, Kamii H, Gobbel GT, Chen SF, Carlson E, Epstein CJ, Chan PH (1996) Attenuation of acute and chronic damage following traumatic brain injury in copper,zinc-superoxide dismutase transgenic mice. J Neurosurg 85:885-891.

Muizelaar JP, Marmarou A, Young HF, Choi SC, Wolf A, Schneider RL, Kontos HA (1993) Improving the outcome of severe head injury with the oxygen radical scavenger polyethylene glycol-conjugated superoxide dismutase: a phase II trial. J Neurosurg 78:375-382.

Murakami K, Kondo T, Epstein CJ, Chan PH (1997) Overexpression of $\mathrm{CuZn-superoxide} \mathrm{dismutase} \mathrm{reduces} \mathrm{hippocampal} \mathrm{injury} \mathrm{after} \mathrm{global}$ ischemia in transgenic mice. Stroke 28:1797-1804.

Nedergaard M, Hansen AJ (1993) Characterization of cortical depolarizations evoked in focal cerebral ischemia. J Cereb Blood Flow Metab 13:568-574.

Nogawa S, Zhang F, Ross ME, Iadecola C (1997) Cyclo-oxygenase-2 gene expression in neurons contributes to ischemic brain damage. J Neurosci 17:2746-2755.

Pasternack RF, Banth A, Pasternack JM, Johnson CS (1981) Catalysis of the disproportionation of superoxide by metalloporphyrin III. J Inorg Biochem 15:261-267.

Patel M, Day BJ, Crapo JD, Fridovich I, McNamara JO (1996) Requirement for superoxide in excitotoxic cell death. Neuron 16:345-355.

Peters O, Back T, Lindauer U, Busch C, Megow D, Dreier J, Dirnagl U (1998) Increased formation of reactive oxygen species after permanent and reversible middle cerebral artery occlusion in the rat. J Cereb Blood Flow Metab 18:196-205.

Piantadosi CA, Zhang J (1996) Mitochondrial generation of reactive oxygen species after brain ischemia in the rat. Stroke 27:327-332.

Pineda JA, Aono M, Sheng H, Lynch J, Wellons JC, Laskowitz DT, Pearlstein RD, Bowler R, Crapo JD, Warner DS (2001) Extracellular superoxide dismutase overexpression improves behavioral outcome from closed head injury in the mouse. J Neurotrauma 18:625-634.

Racker E (1950) Spectrophotometric measurements of the enzymatic formation of fumaric and cis-aconitic acids. Biochem Biophys Acta $4: 211-214$.

Rupalla K, Allegrini PR, Sauer D, Wiessner C (1998) Time course of microglia activation and apoptosis in various brain regions after permanent focal cerebral ischemia in mice. Acta Neuropathol 96:172-178.

Sankarapandi S, Zweier JL, Mukherjee G, Quinn MT, Huso DL (1998) Measurement and characterization of superoxide generation in microglial cells: evidence for an NADPH oxidase-dependent pathway. Arch Biochem Biophys 353:312-321.

Sheng H, Brody T, Pearlstein RD, Crapo J, Warner DS (1999a) Extracellular superoxide dismutase deficient mice have decreased resistance to focal cerebral ischemia. Neurosci Lett 267:13-17.

Sheng H, Bart RD, Oury TD, Pearlstein RD, Crapo JD, Warner DS (1999b) Mice overexpressing extracellular superoxide dismutase have increased resistance to focal cerebral ischemia. Neuroscience 88: $185-191$.

Sheng H, Kudo M, Mackensen GB, Pearlstein RD, Crapo JD, Warner DS (2000) Mice overexpressing extracellular superoxide dismutase have increased tolerance to global cerebral ischemia. Exp Neurol 163:392-398.

Smith M-L, Bendek G, Dahlgren N, Rosen I, Wieloch T, Siesjö BK (1984) Models for studying long-term recovery following forebrain ischemia in the rat. 2: A 2-vessel occlusion model. Acta Neurol Scand 69:385-401.

Soehle M, Heimann A, Kempski O (1998) Postischemia application of lipid peroxidation inhibitor U-101033E reduces neuronal damage after cerebral ischemia in rats. Stroke 29:1240-1247.

Spasojevic I, Batinić-Haberle I (2001) Manganese (III) complexes with porphyrins, related compounds as catalytic scavengers of superoxide. Inorg Chim Acta 317:230-242.

Spasojevic I, Batinić-Haberle I, Fridovich I (2000) Nitrosylation of manganese(III) tetrakis(N-ethylpyridinium-2-yl)porphyrin: a simple and sensitive spectrophotometric assay for nitric oxide. Nitric Oxide 4:526-533.

Uyama O, Matsuyama T, Michishita H, Nakamura H, Sugita M (1992) Protective effects of human recombinant superoxide dismutase on transient ischemic injury of CA1 neurons in gerbils. Stroke 23:75-81.

Yamaguchi S, Ogata H. Hamaguchi S, Kitajima T (1998) Superoxide radical generation and histopathological changes in hippocampal CA1 after ischaemia/reperfusion in gerbils. Can J Anaesth 45:226-232.

Yamamoto T, Yuki S, Watanabe T, Mitsuka M, Saito K, Kogure K (1997) Delayed neuronal death prevented by inhibition of increased hydroxyl radical formation in a transient cerebral ischemia. Brain Res $762: 240-242$

Yang G, Chan PH, Chen J, Carlson E, Chen S, Weinstein P, Epstein CJ, Kamii H (1994) Human copper-zinc superoxide dismutase transgenic mice are highly resistant to reperfusion injury after focal cerebral ischemia. Stroke 25:165-170.

Zea Longa E, Weinstein PR, Carlson S, Cummins RW (1989) Reversible middle cerebral artery occlusion without craniectomy in rats. Stroke 20:84-91.

Zhang R-L, Chopp M, Chen H, Garcia JH (1994) Temporal profile of ischemic tissue damage, neutrophil response, and vascular plugging following permanent and transient $(2 \mathrm{H})$ middle cerebral artery occlusion in the rat. J Neurol Sci 125:3-10. 